\title{
Biomass-derived materials for electrochemical energy storages
}

\author{
Lixue Zhang ${ }^{\mathrm{a}}$, Zhihong Liu ${ }^{\mathrm{a}}$, Guanglei Cui ${ }^{\mathrm{a}, *}$, Liquan Chen ${ }^{\mathrm{a}, \mathrm{b}}$ \\ a Qingdao Industrial Energy Storage Research Institute, Qingdao Institute of Bioenergy and Bioprocess Technology, \\ Chinese Academy of Sciences, Qingdao 266101, China \\ ${ }^{\mathrm{b}}$ Key Laboratory for Renewable Energy, Institute of Physics, Chinese Academy of Sciences, Beijing 100190, China
}

\section{A R T I C L E I N F O}

\section{Article history:}

Received 11 April 2014

Received in revised form 28 August 2014

Accepted 22 September 2014

Available online 2 October 2014

\section{Keywords:}

Biomass-derived materials

Electrochemical energy storages

Separators

Binders

Electrode materials

\begin{abstract}
A B S T R A C T
During the past decade humans have witnessed dramatic expansion of fundamental research as well as the commercialization in the area of electrochemical energy storage, which is driven by the urgent demand by portable electronic devices, electric vehicles, transportation and storage of renewable energy for the power grid in the clean energy economy. Li-secondary batteries and electrochemical capacitors can efficiently convert stored chemical energy into electrical energy, and are currently the rapid-growing rechargeable devices. However, the characteristic (including energy density, cost, and safety issues, etc.) reported for these current rechargeable devices still cannot meet the requirements for electric vehicles and grid energy storage, which are mainly caused by the limited properties of the key materials (e.g. anode, cathode, electrolyte, separator, and binder) employed by these devices. Moreover, these key materials are normally far from renewable and sustainable. Therefore great challenges and opportunities remain to be realized are to search green and low-cost materials with high performances. A large number of the properties of biomass materials-such as renewable, low-cost, earth-abundant, specific structures, mechanical property and many others-are very attractive. These properties endow that biomass could replace some key materials in electrochemical energy storage systems. In this review, we focus on the fundamentals and applications of biomass-derived materials in electrochemical energy storage techniques. Specifically, we summarize the recent advances of the utilization of various biomasses as separators, binders and electrode materials. Finally, several perspectives related to the biomass-derived materials for electrochemical energy storages are proposed based on the reported progress and our own evaluation, aiming to provide some possible research directions in this field.
\end{abstract}

(c) 2014 Elsevier Ltd. All rights reserved.

\section{Contents}

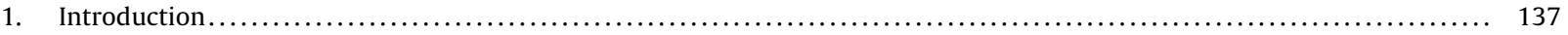

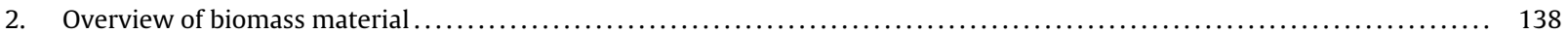

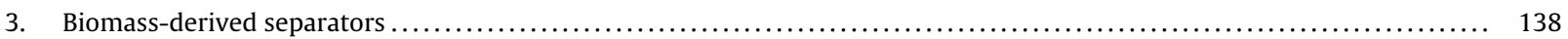

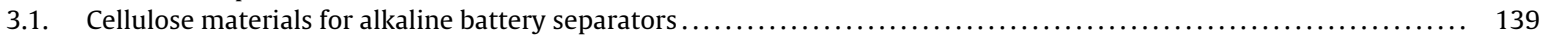

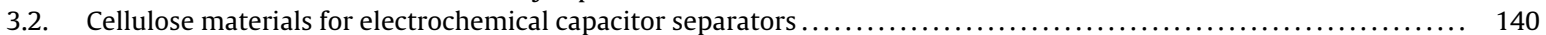

\footnotetext{
* Corresponding author. Tel.: +86 532 80662746; fax: +86 53280662744 .

E-mail address: cuigl@qibebt.ac.cn (G. Cui).
} 


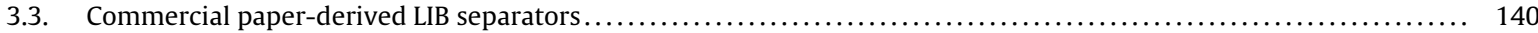

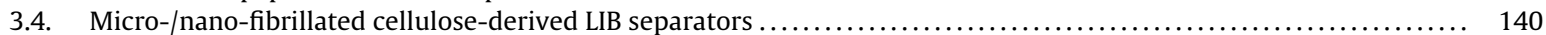

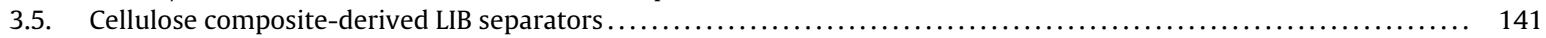

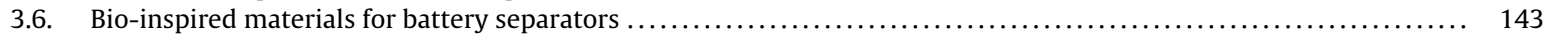

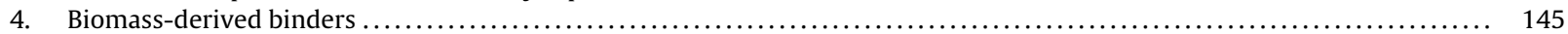

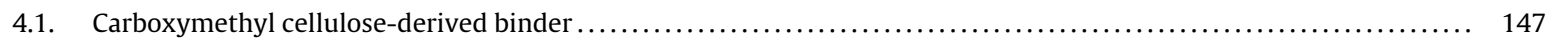

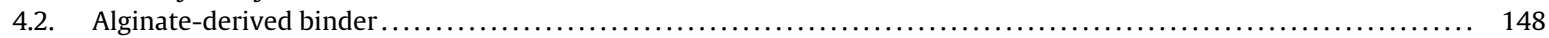

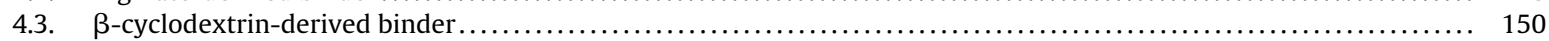

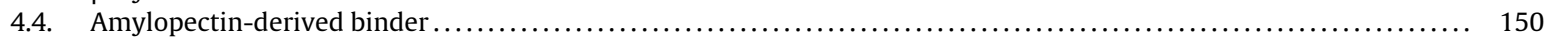

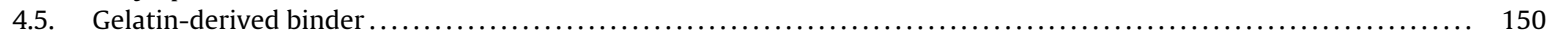

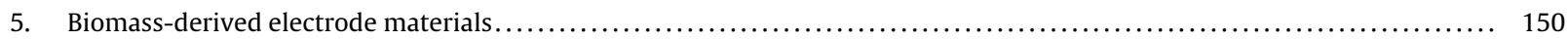

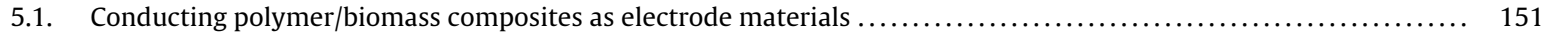

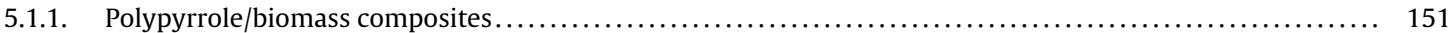

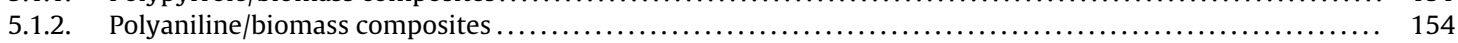

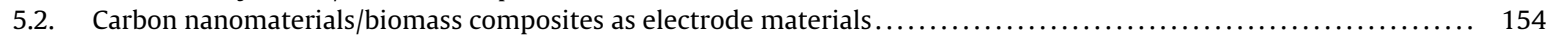

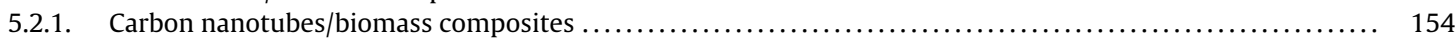

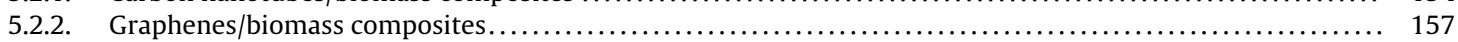

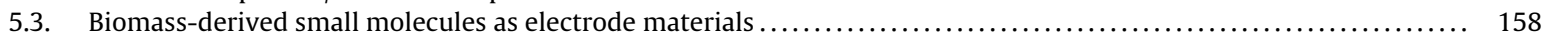

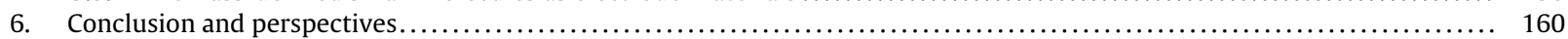

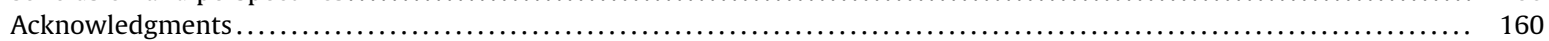

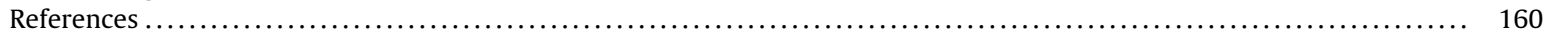

\section{Introduction}

In the 21st century, with the rapid demand of electric vehicles and portable electric devices, a new energy economy is emerging, which is critically based on the cheap and sustainable energy supply. Undoubtedly, to exploit clean, sustainable and secure energy supplies is one of the most important scientific and technical challenges for humans [1-3]. State-of-the-art electrochemical energy storage devices, typically including Li-ion batteries (LIBs) and electrochemical capacitors [4-7], provide a potential and promising solution since they can efficiently store energy from sustainable sources such as the wind and solar power and then work as power sources. These energy storage devices are typically composed of a negative electrode (anode), a positive electrode (cathode), an electrolyte that allows ions transport, a separator that separates the two electrodes, and current collectors that allow current to flow out of the cell to perform work. The overall performance of these energy devices depends intimately on the properties of the materials used. Hence, material science and technology hold the key to new generations of energy storage devices. Numerous materials, including various anodes, cathodes, separators, binders, and electrolytes, are designed and fabricated to improve the performances of LIBs and electrochemical capacitors [4-10].

The principal remaining challenges for the future development and widespread of energy storage, other than performance and safety enhancements, are the reduction of both production and overall device costs, the realization of flexible devices, the identification of environmentally friendly materials and production processes and the development of easily recyclable and up-scalable systems [1-3]. Presently, these electrochemical energy devices mainly depend on the substantive use of components that are far from renewable and sustainable, for instance, inorganic compounds that often require rare metals as electrode materials, expensive polymers as separators and binders, and organic solutions as electrolytes, and so forth [4-7]. Broad applications of electrochemical energy devices require more abundant and inexpensive materials than those currently available. As Armand and Tarascon wrote in 2008, "Researchers must find a sustainable way of providing the power our modern lifestyles demand" [1], a consensus forms across the world that it is highly urgent and desired to decrease the consumption of nonsustainable electrochemical energy device resources by developing materials from easily accessible and renewable sources. Among numerous candidates, biomass-derived materials have gained increasing attention as attractive components of various electrochemical energy devices.

Biomass is biological material derived from living, or recently living organisms. As earth-abundant renewable energy source, biomass is typically used directly via combustion to produce heat, or used indirectly after converting it to various forms of biofuel $[11,12]$. However, the more intriguing and promising utilization of biomass in energy storage is to replace non-sustainable components in electrochemical energy devices, such as separators, binders, and electroactive electrode materials [13-15]. In the recent years, many significant efforts have been put into developing sustainable and high-performance biomass and/or biomass-derived materials for energy storage, and several significant review articles related to these research fields have been presented. Nyholm et al. reported the progress toward flexible polymer and paper-based energy storage devices [13]. Cui et al. reviewed the state-of-the-art flexible energy and electronic devices based on nanostructured papers [14]. Jabbour et al. summarized the progress of cellulose-based LIBs [15]. However, there is no a systemic review related to the applications of diverse biomasses and their polymer derivatives in electrochemical energy storages yet. In this review, we will give a short introduction of biomass materials, and then focus on recent progresses of biomass-derived materials as advanced separators, binders, and electrode materials in electrochemical 


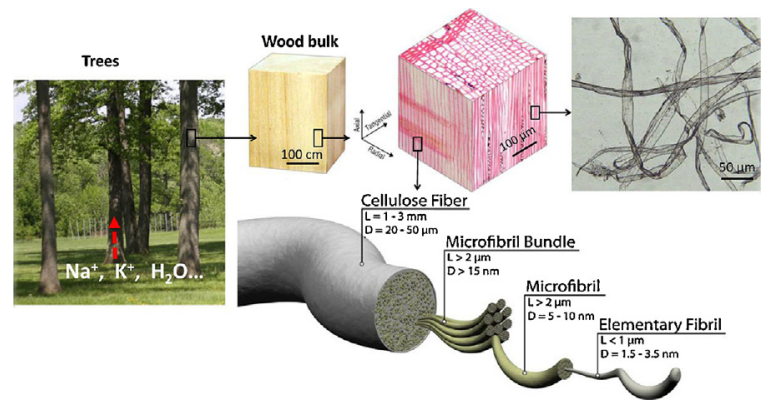

Fig. 1. Hierarchical structure of wood fiber [19]. Copyright 2013. Reproduced with permission from the American Chemical Society.

energy storages, and finally provide an overview and outlook about these fascinating research fields.

\section{Overview of biomass material}

Biomass is all biologically-produced matter based on carbon, hydrogen and oxygen. The estimated biomass production in the world is 146 billion tons a year, consisting of mostly wild plant growth [16]. Biomass most often refers to plants or plant-derived materials, specifically called lignocellulosic biomass. In addition to lignocellulosic biomass, marine organisms also constitute a large part of biomass materials. It is well known that biomass has been widely applied in many fields, and the application of a particular type of biomass depends on the chemical and physical properties of the macromolecules [17]. In this review, several biomass-derivatives materials that have been widely used for energy storage devices, including cellulose, alginate, and some others, are mainly mentioned. The basic information of cellulose and alginate, including manufacture methods, molecular structures and properties, is summarized in Table 1.

As the most important skeletal component in plants, the polysaccharide cellulose is an almost inexhaustible polymeric raw material with fascinating structure and properties. Formed by the repeated connection of D-glucose building blocks, the highly functionalized, linear stiffchain homopolymer is characterized by its hydrophilicity, biodegradability, broad chemical modifying capacity, and its formation of versatile semicrystalline fiber morphologies [18]. The nature of cellulose fibers is affected by the source of the raw material stock, e.g. wood pulp versus cotton linters, and the chemistry and mechanics of the fibers forming process. Interestingly, cellulose exists in hierarchical structure from micrometric cellulose fibers to nanocelluloses and water/solvent soluble cellulose derivatives, which promises an expected porosity (Fig. 1) [19]. For instance, thousands of microfibrils cellulose assembles one tracheid in wood fiber, which has a multichannel, mesoporous structure and allows for the intercellular transportation of water and mineral salts (Fig. 1) [19]. Over the last 10 years, celluloses, especially nanocellulose, have attracted an ever increasing attention for the production of cellulose based nanocomposite materials, due to their high strength and stiffness combined with low weight, biodegradability and renewability [20].

Marine polysaccharides, including alginate, chitin, agar and carrageenan, can be easily obtained from diverse marine organisms such as fishery products, seaweeds, microalgae, microorganisms, and corals [21]. Since these organisms inhabit in a very diverse marine environments, marine polysaccharides exhibit some unique properties, which are useful in a variety of applications such as food technology, biotechnology, pharmacy, and chemical industries. For instance, alginate is a naturally occurring anionic polymer typically obtained from brown seaweed, and typically alginate is a linear copolymer with homopolymeric blocks of (1-4)-linked $\beta$-D-mannuronate and its C-5 epimer $\alpha$-L-guluronate residues. Due to its biocompatibility, low toxicity, relatively low cost, and mild gelation by addition of cations, alginate is widely used in food industry and pharmaceutical industry.

\section{Biomass-derived separators}

Battery separator, a porous membrane placed between electrodes of opposite polarity, serves to prevent contact between the positive electrode and the negative electrode and also plays a very important role in improving battery performance and enhancing its safety $[22,23]$. In the present battery production, the separator is impregnated typically into a mixture of supporting electrolyte (e.g. $\mathrm{LiPF}_{6}$ salts) and organic solvents such as ethylene carbonate (EC), ethyl methyl carbonate, and diethyl carbonate. A number of factors must be considered in selecting the suitable separator for a practical battery, and the general characteristic and requirements of separators are well illustrated in the review by Aoroa and Zhang (as shown in Table 2) [24]. Actually the data summarized in Table 2 are mainly focus on the polyolefin separators, and these parameters for nonwoven separators are somewhat depend on their specific materials and configurations.

Many researchers are interested in high-power LIBs due to their excellent properties, resulting in the expansion in the use of large-scale LIBs in the power market and power grid areas. These emerging markets have led to new demands on separators for LIBs $[22,23,25]$. The most widely used separators in LIBs are fabricated from polyolefins, predominantly polyethylene (PE), polypropylene (PP) and their copolymers. These polyolefin separators have many advantageous attributes in terms of practical application to commercialized LIBs, such as low cost, proper mechanical strength and pore structure, electrochemical stability, and thermal shutdown properties [22,26]. However, these separators suffered from a severe challenge in large shrinkage ratio at relatively high temperature of more than $100^{\circ} \mathrm{C}$. Moreover, their intrinsically hydrophobic character and low porosity raise serious concerns over insufficient electrolyte wettability, which could directly impair ionic transport through the separators and deteriorate cycle lives. Recently many approaches have been proposed to improve this insufficient heat resistance of microporous polyolefin separators including the ceramic coating on the surface of microporous membrane [27] and surface grafting modification using plasma treatments or electron beam 
Table 1

The basic information of two typical biomass materials.

\begin{tabular}{lll}
\hline Biomass & Manufacture methods \\
Cellulose & $\begin{array}{l}\text { Extract from plants; fibrillation and } \\
\text { refining of cellulose pulp; bacterial } \\
\text { synthesis }\end{array}$ \\
Alginate & Extract from seaweeds
\end{tabular}

irradiation $[28,29]$. The most used fillers incorporated into the polymer hosts are inert oxide ceramics $\left(\mathrm{Al}_{2} \mathrm{O}_{3}, \mathrm{SiO}_{2}\right.$, $\mathrm{TiO}_{2}$ ) and molecular sieves (zeolites) with the main function of increasing wettability, mechanical stability and thermal dimensional stability of the separators [30,31]. Despite these advances, it is difficult to fully ensure electrical isolation between electrodes due to their inessential poor thermal shrinkage and weak transverse mechanical properties for intrinsic polyolefin materials at elevated temperature $[32,33]$. In addition, the high processing cost and exhaustible fossil derived materials of polyolefin separators remains a critical burden on manufacture boosting and environments. Hence, a more advanced separator that can overcome these stringent shortcomings of polyolefin separators is urgently needed for facilitating the successful development of high-energy density/high-power density cells.

Luckily, sustainable biomass-derived separators including cellulose, chitin and alginate, that exhibit superior wettability and thermal stability, are demonstrated as promising alternatives to conventional polyolefin separators for state-of-the-art electrochemical energy storage devices. These hydrophilic stiff-chain homopolymers endow super solvophilicity, wettability, recycling, accessible to electrolyte and better thermal stability (over $230^{\circ} \mathrm{C}$ ) than polyolefin. Actually, cellulose and cellulose composite separators were initially explored for using in alkaline batteries. In recent 30 years, cellulose nonwoven has been widely explored as separators for LIBs and electrochemical capacitors. The common properties of biomass-based separators for alkaline batteries, electrochemical capacitors and LIBs include: (1) favorable separator surface and interface wettability by electrolyte, (2) high ion conductivity, and (3) large-scale production with low cost.

\subsection{Cellulose materials for alkaline battery separators}

About 70 years ago, the utility of regenerated cellulose membrane as a battery separator was recognized as a forward step which advanced the silver/zinc battery to a practical system. In 1941, Henri Andre, a pioneer of regenerated cellulose membrane, discovered that the short life of the silver/zinc battery system could be considerably improved by the introduction of a suitable cellulose semipermeable separator [34]. Then, for their excellent wettability, low processing cost, high porosity, good mechanical properties and light weight, paper sheets prepared using alkaline-resistant cellulose pulp or other cellulosic components were successfully used in a series of commercially available alkaline batteries including alkaline manganese cell, nickel/cadmium industrial batteries, zinc/air cells, silver/cadmium batteries, as well as in silver/zinc batteries [35]. Although the electrolytes are different from one to another, the similar fundamental properties and problems for separator films are commonly observed in these systems. Harlan Lewis studied the properties of cellulosic separator and their relationships with the cycle- and wet-life information from model

Table 2

General parameters for LIB separators.

\begin{tabular}{|c|c|c|}
\hline Parameter & Goal & Test method (N.A. = not available) \\
\hline Sale price $\left(\$ \mathrm{~m}^{-2}\right)$ & $<1.00$ & $\begin{array}{l}\text { The American Society for Testing and } \\
\text { Materials (ASTM) test method } \\
\text { D5947-96 }\end{array}$ \\
\hline Thickness (um) & $<25$ & \\
\hline Permeability (MacMullin, dimensionless) & $<11$ & \\
\hline Wettability & $\begin{array}{l}\text { Complete wet out in typical battery } \\
\text { electrolytes }\end{array}$ & N.A. \\
\hline Chemical stability & Stable in battery for 10 year & N.A. \\
\hline Pore size (um) & $<1$ & ASTM test method E128-99 \\
\hline Puncture strength & $>300 \mathrm{~g} / 25.4 \mu \mathrm{m}$ & ASTM F1306-90 \\
\hline Thermal stability & $<5 \%$ shrinkage after $60 \mathrm{~min}$ at $90^{\circ} \mathrm{C}$ & ASTM D1204 \\
\hline Purity & $<50 \mathrm{ppm} \mathrm{H}_{2} \mathrm{O}$ & \\
\hline Tensile strength (for spirally wound) & $<2 \%$ offset at $100 \mathrm{psi}$ & ASTM test method D882-00 \\
\hline
\end{tabular}

Reproduced with permission from Ref. [24], Copyright 2004 American Chemical Society. 
electrochemical cells as a functional of separator composition on an alkaline chemistry rechargeable cell set [36].

Alkaline battery accounts for $80 \%$ of manufactured batteries in the US and over 10 billion individual units produced worldwide, and the cellulose based separators for alkaline battery are still one of the intensive research focuses. Recently, some new progress related to cellulose materials for alkaline battery separator was achieved. Wang et al. fabricated alkaline $\mathrm{Zn} / \mathrm{MnO}_{2}$ separator with an ultra-fine fibrillated Lyocell fibers by wet-laid nonwoven method, and the resulting separators manifested better properties than commercial separator especially in thickness and pore size [37]. Similarly, Toshimitsu Harada disclosed an alkaline battery composite separator including alkali-resistance synthetic fiber, fibrillated organic solventspun cellulose fiber and mercerized pulp, wherein the cellulose fiber intertwines with the mercerized pulp. This kind of composite separator exhibited excellent properties in denseness, electrolyte retention capability, and alkali resistance and great stiffness strength [38]. Most recently, Nippon Kodoshi Corporation developed an alkaline battery separator on the basis of cellulose. This separator is constructed by including 20-90 mass\% cellulose fiber and having the remains being an alkali-resistant synthetic fiber, and can suppress reduction in the characteristics of the alkaline battery after storage [39].

\subsection{Cellulose materials for electrochemical capacitor separators}

Electrochemical capacitors store the energy at the electrode/electrolyte interface of high surface area materials, such as porous carbons or some metal oxides. Although their energy densities are somewhat low, electrochemical capacitors possess of many important benefits, such as high power density, long lifetime, low cost, good cycle performance and rate capability, etc. Electrochemical capacitors have been commercially available for more 30 years, and have been widely applied in consumer electronic products, (alternative) power source, and electric vehicles. [7,40].

In principle, electrochemical capacitor can work without a separator if a suitable distance between electrodes can be kept. However, practically, separators are necessary for the electrochemical capacitors to prevent from short circuits. Owing to the large market, the separator of electrochemical capacitors should be quite low in price and quite high in quality. Numerous studies have been demonstrated that cellulose-derived separators are very suitable for electrochemical capacitors applications, due to their low cost and high porosity (in the order of 45-90\%) [7]. Currently, numerous cellulose based paper products are available for use as separator membranes in commercially available electrochemical capacitor systems. Such products include single-sheet cellulose fiber materials, multi-sheet cellulosic and composite materials with various densities which ostensibly yield the desirable properties, i.e., electrolyte absorption, electronic insulation, and physical strength [41]. Although such separator papers perform quite well in the intended physical compression type of electrochemical capacitors, the resistance between these papers and the desirable cell electrode compositions (particularly in preferred thermal laminating procedures), restricts use of these papers in the fabrication of unitary laminated cell structures [42]. In addition, paper separators often suffer from performance deterioration at high voltage and water contamination in electrochemical capacitors, thus it is critical to overcome these obstacles for the development of paper separator-based capacitors.

\subsection{Commercial paper-derived LIB separators}

Some cellulose papers, which are manufactured using commercial cellulose papers, as advanced separators of lithium-based batteries have been reported. In 1996, Kuribayashi carried out a systematic investigation on the use of thin hybrid cellulose separators for LIBs. These paper separators, comprising fibrilliform cellulosic fibers embedded in a microporous cellulosic matrix soaked with an aprotic solvent, were supplied by Nippon Kodoshi Corporation and Tomiyama Pure Chemical Industry. The proposed separators showed fair-to-moderate physical strength, an apparent completely freedom from pinholes, and a comparable impedance to that of conventional polyolefin separators [43]. The commercial rice paper, a low cost and highly porous, flexible cellulose membrane, invented over a thousand years ago in China for traditional Chinese painting and calligraphy, was recently explored for the application as separator of LIBs, which exhibit fair cycling electrochemical stability at low current density [44].

The cellulosic papers directly as separators suffer from moisture absorption owing to the hygroscopic nature. The moisture content of cellulose fibers can range between 2 and $12 \times 10^{4} \mathrm{ppm}$ [45], which severely exceeds the humidity requirement of a LIB electrolyte (not exceed ca. 20-50 ppm). A high humidity condition usually leads to the degradation of lithium salts, particularly $\mathrm{LiPF}_{6}$ hydrolysis and HF formation [46]. Nevertheless, as demonstrated in recent works, this apparent limitation of moisture accessibility can be solved by prolonged thermal treatment over $120^{\circ} \mathrm{C}$ owing to its superior thermal stability of cellulose which allows removing most of water adsorbed on cellulose [47].

Due to the high thermal stability and cost-effective of cellulose materials, the commercial cellulose papers can be used as separators for LIBs. However, the macro/ microfiber-based cellulose papers face some stringent limitations in securing a satisfactory porous configuration (particularly, pore size and pore size distribution, and thermal shutdown effect), and mechanical strength and flammable characteristic, which in turn hamper their application as LIB separators. As a result, it seems not very suitable to directly use commercial papers as LIB separators.

\subsection{Micro-/nano-fibrillated cellulose-derived LIB separators}

Micro-/nano-fibrillated elluloses, consisted of highly crystalline domains and attractive nanoporous structure, possess excellent mechanical property and attractive porous structure. These fascinating characteristics would endow micro-/nano-cellulose membrane as a very 

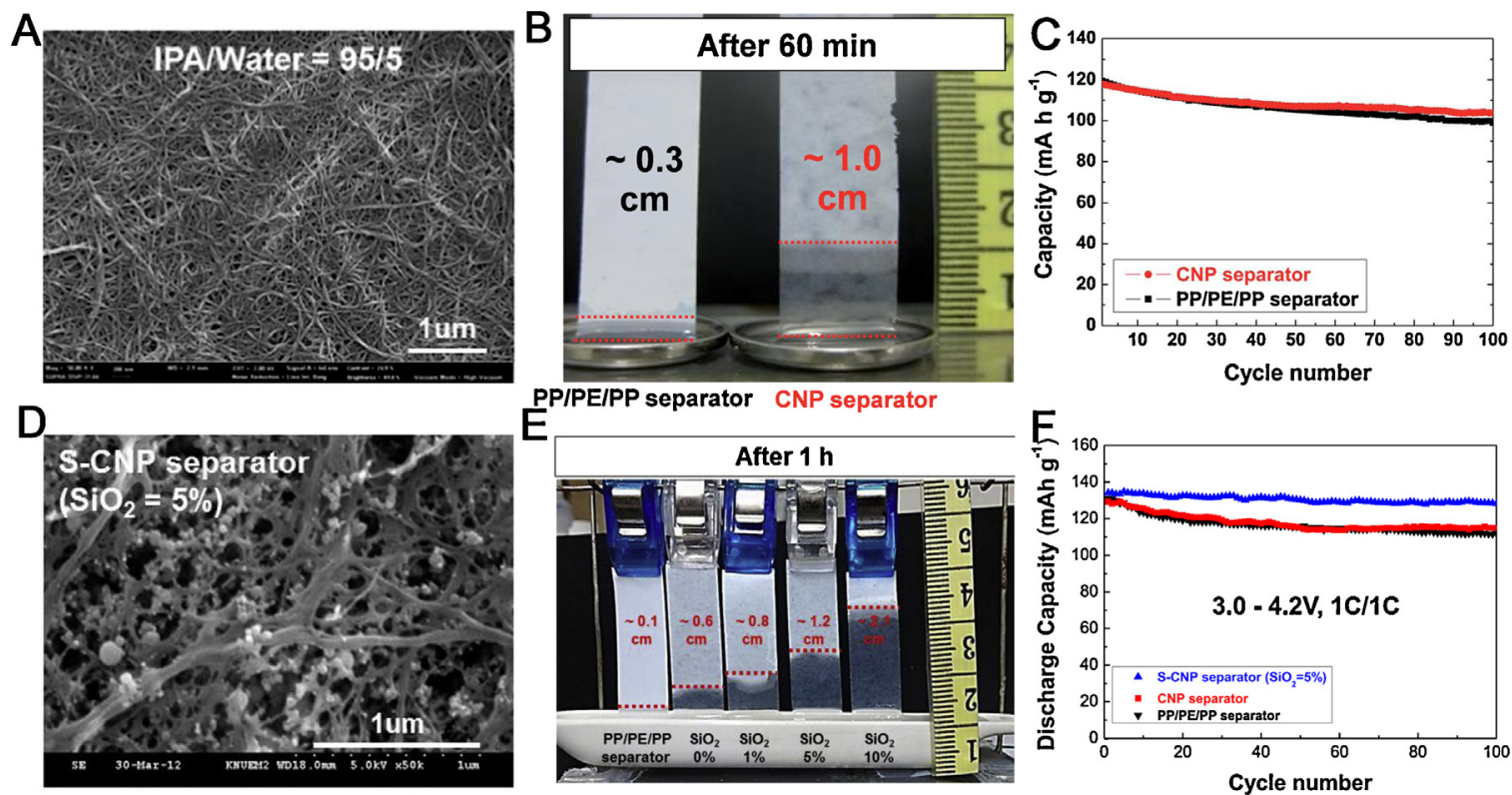

PPIPEIPP separator CNP separator
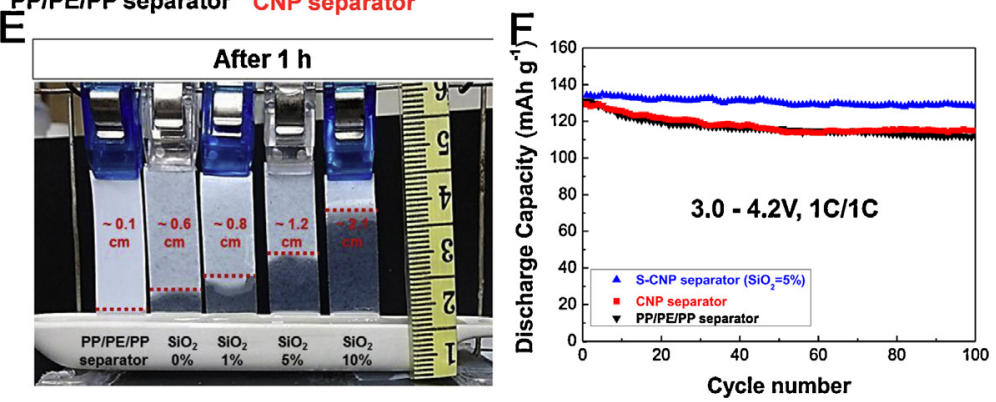

Fig. 2. CNFs paper (CNP)-derived separators by Lee group: (A) scanning electron microscopy (SEM) image of CNP separator. (B) Comparison of liquid electrolyte $\left(1 \mathrm{M} \mathrm{LiPF}_{6}\right.$ in $\left.\mathrm{EC} / \mathrm{DEC}=1 / 1, \mathrm{v} / \mathrm{v}\right)$ immersion-height between the PP/PE/PP separator and CNP separator. (C) Comparison of cycling performance of cells assembled with PP/PE/PP separator or CNP separator [48]. Copyright 2012. Reproduced with permission from the Royal Society of Chemistry. (D) SEM image of $\mathrm{SiO}_{2}$ decorated CNP (S-CNP) separator $\left(\mathrm{SiO}_{2}=5 \mathrm{wt} . \%\right)$. (E) Comparison of liquid electrolyte $\left(1 \mathrm{M} \mathrm{LiPF}_{6}\right.$ in EC/DEC $\left.=1 / 1, \mathrm{v} / \mathrm{v}\right)$ immersion-height between the PP/PE/PP separator, CNP separator, and $\mathrm{S}$-CNP separators $\left(\mathrm{SiO}_{2}=1,5,10\right.$ wt.\%). F) Comparison of cycling performance of cells assembled with CNP separator, S-CNP separators, or PP/PE/PP separator [52]. Copyright 2013. Reproduced with permission from Elsevier Ltd.

promising separator for LIBs. In the most recent years, Lee and his colleagues devoted much contribution in the field of nanocellulose-based separators. They developed eco-friendly cellulose nanofibers (CNFs) paper-derived separators with a salient feature of electrolyte-philic, nanoscale labyrinth structure established between closely piled nanocelluloses. The unusual porous structure is fine-tuned by varying the composition ratio of the solvent mixture (isopropyl alcohol (IPA)/water) in the CNFs suspension, wherein IPA is introduced as a CNFsdisassembling agent while water promotes dense packing of CNFs. For example, when the IPA content is 95\%, the CNFs separator provides a porous structure containing many nanopores formed between highly interconnected CNFs (Fig. 2A). Compared with the PP/PE/PP separator, the CNFs separator presents a much improved wettability of liquid electrolyte (Fig. 2B). Due to the nanoporous structure and strong affinity for liquid electrolyte, these CNFs paper-derivated separator shows good cycling performance (Fig. 2C) and rate capability [48].

However, CNFs paper separators suffer from a limitation in providing highly-porous structure, which may stagger ionic transport via the liquid electrolyte-filled CNFs paper separator. This structural shortcoming may arise from the dense packing of CNFs for the strong hydrogen bonding between nanocellulose [49-51]. Lee et al. recently designed a colloidal $\mathrm{SiO}_{2}$ nanoparticle-based strategy to tune the porous structure of CNFs paper separators, in which the $\mathrm{SiO}_{2}$ nanoparticles are introduced as a CNFs-disassembling agent instead of IPA. The $\mathrm{SiO}_{2}$ nanoparticles are dispersed between the CNFs and allow loose packing of CNFs, thereby facilitating the formation of a more developed porous structure (Fig. 2D). With increasing the content of hydrophilic $\mathrm{SiO}_{2}$ nanoparticles, the as-prepared $\mathrm{SiO}_{2}$-CNFs exhibit the greater and greater electrolyte immersion-height than the $\mathrm{PP} / \mathrm{PE} / \mathrm{PP}$ separator (Fig. 2E). With well-developed porous structure and optimized membrane properties, the $\mathrm{SiO}_{2}$-CNFs paper separator greatly improves the cycle performance and rate capability (Fig. 2F) [52].

Although the above developed CNFs paper-derived separators exhibited an enhanced cell performance, these separators still suffered from a poor mechanical strength and the fabrication process is somewhat complicated. It still remains a challenge to produce nanocellulose separator in a large-scale, low-cost and environmental friendly approach. To simplify the fabrication of CNFs-based separator, Lee et al. also developed a new method, which relies on simply mixing cellulose nanofibrils and a pore-forming resin. The pore-forming resin, consisting of polyethylene glycol, polypropylene alcohol, PP, and hydroxyl cellulose, was explored to form micropores [53].

\subsection{Cellulose composite-derived LIB separators}

In recent years, many efforts have been made to improve the porous structure, mechanical property and electrochemical performance of the cellulose based separators for LIBs. Among them, incorporating other polymer materials with the cellulose nonwoven to form composite separators seems a very promising approach. It can improve the mechanical property of cellulose separator, and at the same time, it might bring a synergetic effect for the composite separator. The principal features of battery separators 
based on cellulose derived composite materials are summarized in Table 3.

In order to improve the separator performance with minimal water adsorption and enlarged voltage window for high energy battery, Cui et al., from Chinese Academy of Sciences, explored a cellulose-based composite nonwoven via an electrospinning technique for LIB separator. The nonwoven mat of cellulose was prepared by deacetylation, and then formed composite with poly(vinylidene fluoride-co-hexafluoropropylene) (PVDF-HFP) by dip coating, and followed by calendaring. Compared with cellulose nonwoven, the cellulose/PVDF-HFP composite nonwoven shows smaller pore sizes and uniform pore distribution (Fig. 3A and B), which might be in favor of mitigating self-discharge and achieving uniform current density at high rates. The cells using such composite separator displayed better rate capability (Fig. 3C) and enhanced cycling stability (Fig. 3D) when compared with the cell using commercialized PP separator under the same conditions. This attractive result owned to its superior interfacial stability and high ionic conductivity of cellulose/PVDF-HFP composite separator [54].

Polysulfonamide (PSA) is one kind of high performance synthetic polymers known for its excellent thermal, mechanical, dielectric properties and chemical resistance. To improve overall performance of cellulosed-based separator, Cui et al. fabricated cellulose/PSA composite membrane from mixture of microfibrillar cellulose and PSA via a facile papermaking process (Fig. $4 \mathrm{~A}$ ). $\mathrm{LiFePO}_{4} /$ lithium cell employing cellulose/PSA separator exhibited perfect charge-discharge capability even at $120^{\circ} \mathrm{C}$ (Fig. 4B), indicting a superior thermal dimensional stability [55].

Very recently, Cui et al. successfully explored a sustainable, heat-resistant and flame-retardant cellulose-based composite nonwoven (FCCN) separator for LIBs [56]. This FCCN, which presented distributed pores with diameters ranging from 100 to $200 \mathrm{~nm}$, was made from cellulose pulp, sodium alginate, flame retardant and silica by papermaking approach. It was demonstrated that this FCCN separator possessed superior heat tolerance (Fig. 5A), excellent flame retardancy (Fig. 5B) and satisfactory mechanical strength. Owing to the facile ion transport and excellent interfacial compatibility of FCCN, the $\mathrm{LiCoO}_{2} /$ graphite cell using FCCN separator exhibited better rate capability (Fig. 5C) and cycling retention than that using PP separator. Furthermore, the $\mathrm{LiFePO}_{4} / \mathrm{Li}$ cell with FCCN separator delivered a stable cycling performance and thermal dimensional stability even at $120^{\circ} \mathrm{C}$ (Fig. 5D) [56].

Mitsubishi Paper Mills Ltd also reported many natural cellulose/synthetic polymer fiber composite separators for LIBs [57-60]. Due to the good heat resistance of poly(ethylene terephthalate) (PET) fiber nonwoven and cellulosic materials, the cellulose/PET composite separator (NanoBase2) shows excellent heat resistance even at $220^{\circ} \mathrm{C}$, indicating a higher margin of safety. Meanwhile, the NanoBase2 composite shows improved mechanical strength and excellent protection against foreign particle because of the rich contents of ceramic particle. In addition to the inherent advantages of nonwoven kept after the ceramic coating, such as electrolyte wettability and ion conductivity, these composite separators displayed the

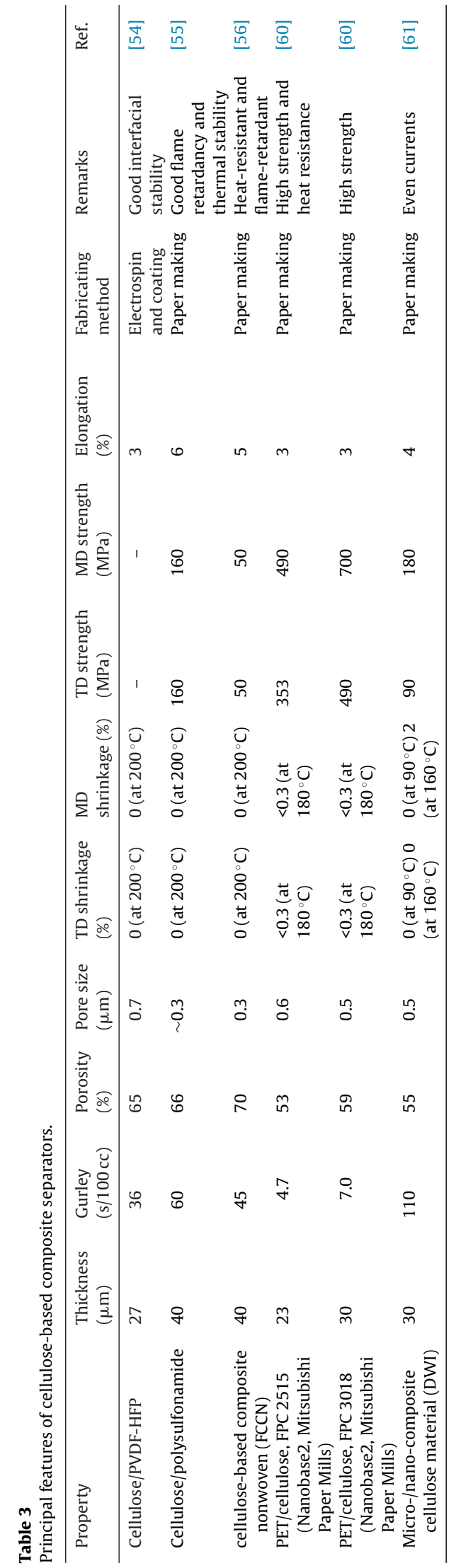



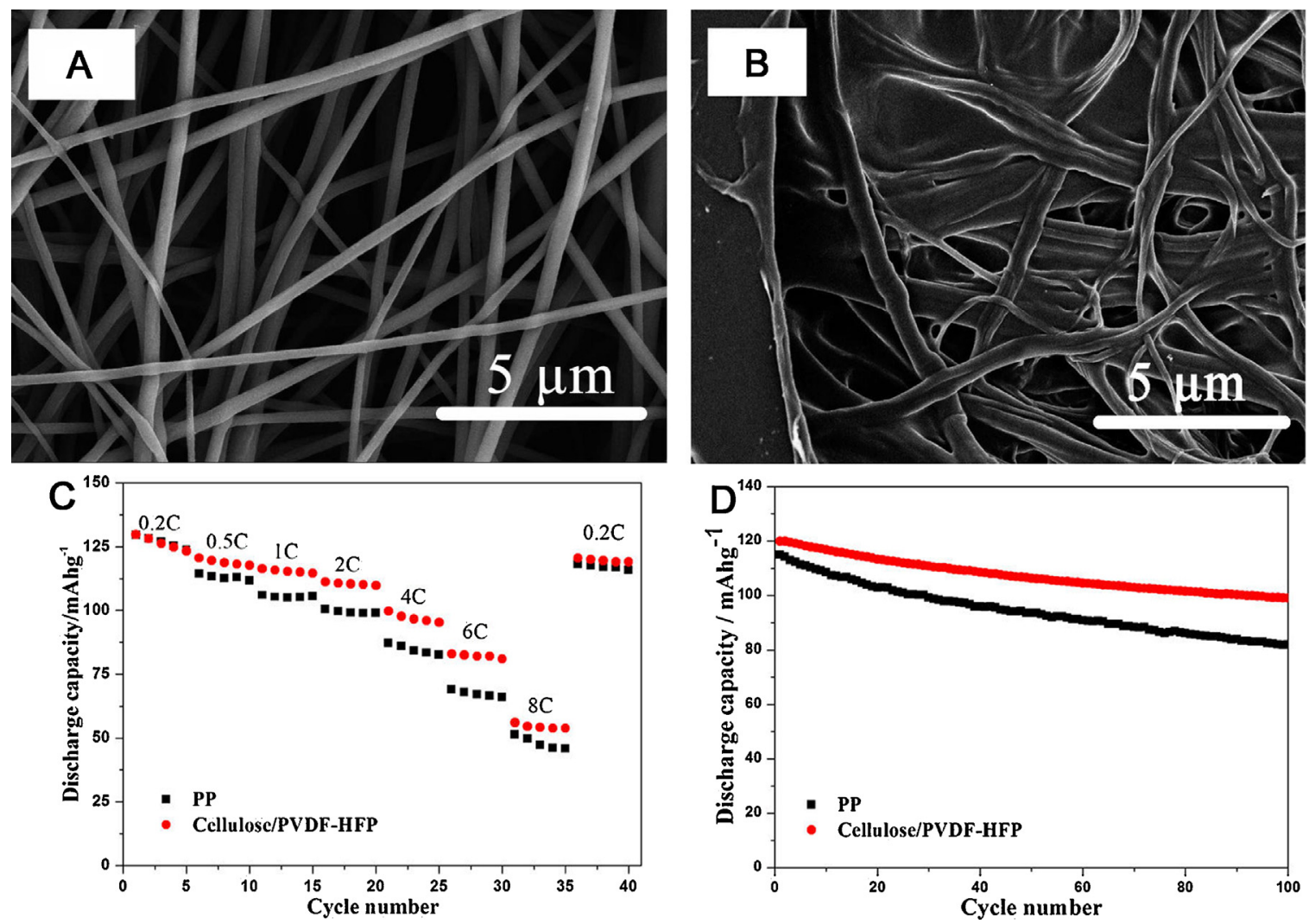

Fig. 3. Typical SEM image of the cellulose nonwoven (A) and cellulose/PVDF-HFP composite nonwoven (B), and comparison of rate capability (C) and cycling performance (D) of $\mathrm{LiCoO}_{2}$ /graphite cells assembled with PP separator and cellulose/PVDF-HFP composite separator [54].

Copyright 2013. Reproduced with permission from the American Chemical Society.

longer cycle life than that of commercial polyolefin microporous membrane separators.

Jim Schaeffer and Brian Morin, from Dreamweaver International (DWI), fabricated a high-performance separator for LIBs combination of CNFs and cellulose microfibers. When the microfibers and nanofibers are combined, the cellulose composite material has the strength and openness of the microfiber scaffolding while the nanofibers drape over the microfibers strategically, closing down the pore size and maintaining a high permeability for ions. For safety testing including Nail penetration, over charge, short circuit, hot box and temperature cycling tests, this DWI separator of $30 \mu \mathrm{m}$ in small $50 \mathrm{mAh}$ pouch cells showed identical performance with that of trilayer PP/PE separators of $25 \mu \mathrm{m}$. Moreover, the DWI separator delivered a higher energy at large discharge rates for all cell builds compared with several other film-based separators [61].

\subsection{Bio-inspired materials for battery separators}

In addition to the battery separators with biomass materials as the skeleton material, bio-inspired surface coating is another practical method to overcome the shortcomings of conventional polyolefin separators. Messersmith et al. noticed the mussel's strong adhesion
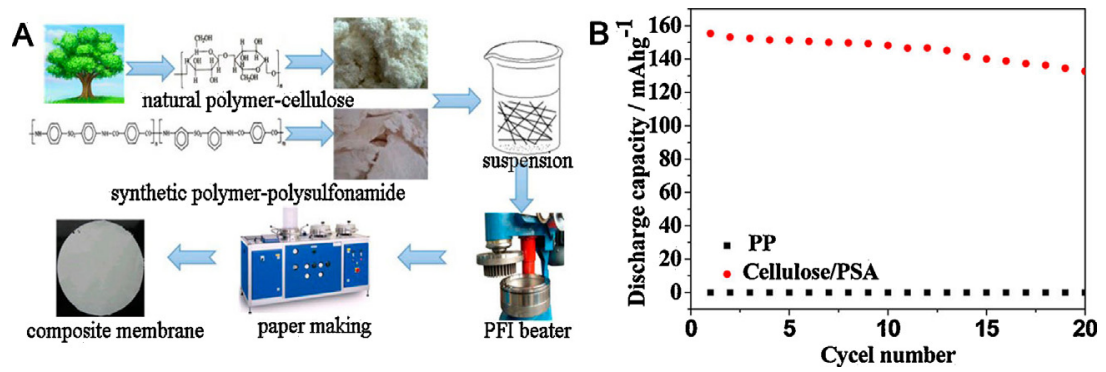

Fig. 4. (A) Schematic of the preparation of cellulose/PSA composite membrane for LIB separator, and (B) comparison of cycling performance of LiFePO $4 /$ Li cells assembled with PP separator and cellulose/PSA composite separator at $120^{\circ} \mathrm{C}[55]$. Copyright 2014. Reproduced with permission from the American Chemical Society. 

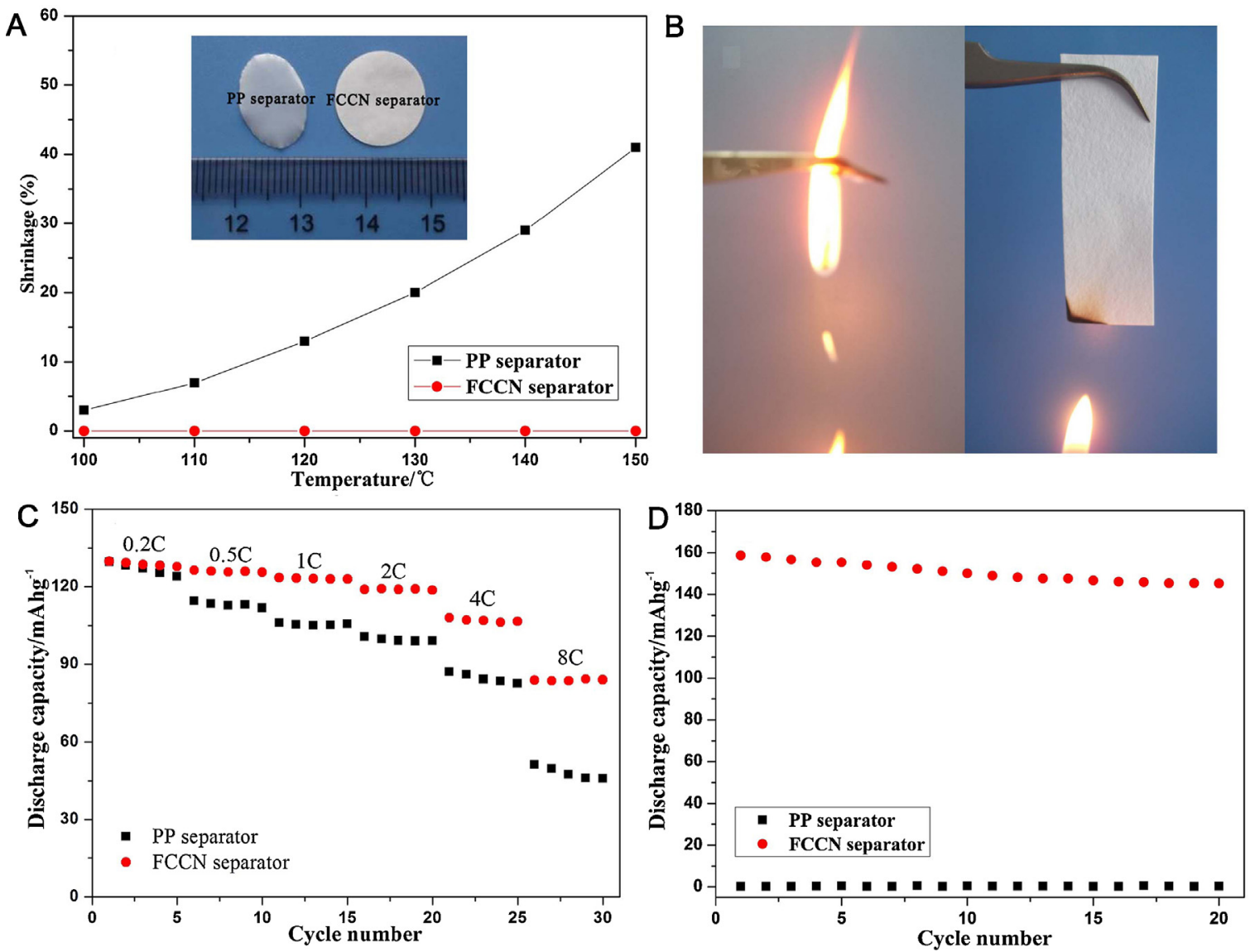

Fig. 5. (A) Thermal shrinkage behavior of FCCN and PP separators with increasing the temperature, and the inset is the photograph of FCCN and PP separators after treating for $0.5 \mathrm{~h}$ at $150^{\circ} \mathrm{C}$. (B) Combustion behavior of FCCN and PP separators, showing the flame retardancy characterization of FCCN separator. (C) Comparison of rate capability of $\mathrm{LiCoO}_{2}$ /graphite cells assembled with FCCN separator and PP separator. (D) Comparison of cycling performance of $\mathrm{LiFePO}_{4} / \mathrm{Li}$ cells assembled with FCCN separator and PP separator at $120^{\circ} \mathrm{C}[56]$.

Copyright 2014. Reproduced with permission from the Nature Publishing Group.
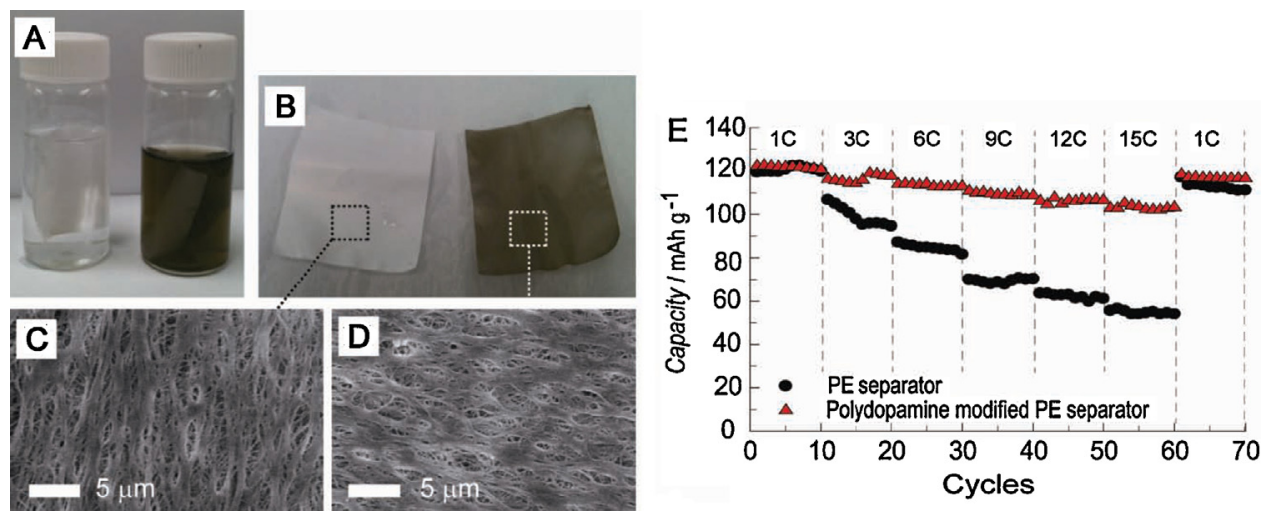

Fig. 6. Preparation and application of the polydopamine-modified PE separator. (A) Photograph of PE separators immersed in dopamine solution without (left) and with (right) the buffer treatment at pH 8.5 after 24 h. (B) Photograph of PE separators without (left) and with (right) the polydopamine modification. (C) SEM image of PE separator and (D) SEM image of PE separator with the polydopamine treatment, indicating that the polydopamine film is thin enough and does not modify the original morphology of PE separator. (E) A comparison of discharging capacities between the pouch-type half-cell with polydopamine

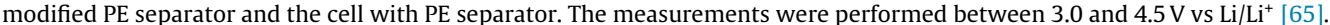

Copyright 2011. Reproduced with permission from WILEY-VCH Verlag GmbH \& Co., KGaA. 
ability onto virtually all types of surfaces and identified 3,4dihydroxy-L-phenylalanine and lysine peptides in Mytilus edulis foot protein 5 of mussel's adhesive threads as the origins of the extraordinarily strong adhesion. Based on this interesting finding, they recognized that dopamine, a commercially available chemical, containing both catechol and amine groups, can function as a basis for the strong adhesion for various applications [62-64]. Inspired by the above-mentioned works, Pyou et al. developed a simple dipping process to generate polydopamine-coated PE separators. After treatment, the color of PE separator changes to black-brown, indicating the spontaneous deposition of thin polydopamine film on the surface of PE (Fig. 6A and B). SEM images show that there is no obvious structure change after the polydopamine coating (Fig. 6C and D). Meanwhile, after the polydopamine coating, the surfaces of the separators transfer hydrophilic from hydrophobic and the wetting ability of electrolyte solvents on the separators is greatly improved. Taking advantage of the hydrophilic surface character, the modified PE separators exhibit significantly improved power performance without sacrificing the original advantages of PE separators (Fig. 6E) [65]. Importantly, it was then demonstrated that lithium-metal anodes in LIBs with mussel-inspired polydopamine-coated separators exhibited excellent cycle life, which results from the suppression of Li-dendrite growth and the uniform $\mathrm{Li}$ ionic flux originating from the increased electrolyte uptake, as well as the strong mussel-inspired catecholic adhesion onto to the Li surfaces [66].

In order to improve the mechanical strength of cellulose-based battery separator, especially in wet condition, Cui et al. explored the polydopamine treatment of cellulose membrane by a facile and low-cost papermaking process (Fig. 7A) [67]. It was found that the composite membrane possessed compact porous structure, superior mechanical strength and excellent thermal dimensional stability. Compared with those of commercial PP separator and pristine cellulose separator, the cells using the composite separator displayed a superior rate capability (Fig. 7B) and excellent capacity retention (Fig. 7C). The bio-inspired polydopamine treatment has been demonstrated to be a versatile approach, and thus may be applicable to other separators with similar surface properties, to improve the surface property and mechanical strength.

\section{Biomass-derived binders}

As to LIBs, electrochemical capacitors and other energy storage devices, there have been extensive studies on electrode materials, separators, electrolytes and additives to achieve improvement of the device performance $[68,69]$. Compared with the significant progress in these components, however, binders have not yet attracted extensive interests till now due to its characteristic of inactive material [70-72]. Typically, the binder provides structural integrity at relatively low mass fractions, bringing together the active material, the carbon black and the current collector. Although a binder is electrochemically inactive, considerable researching indicates that it can have a significant influence on the electrode performance especially for the newly-developed Si-based electrodes.
In lithium batteries, a suitable binder must meet the following prerequisites [73]. (i) The binder is usually characteristic of polar groups such as $-\mathrm{OH},(\mathrm{C}=\mathrm{O})-\mathrm{OH}$, $\mathrm{O}-(\mathrm{C}=\mathrm{O}) \mathrm{R},-\mathrm{SO}_{3} \mathrm{H},-\mathrm{CN}$ or other groups in the side chain, delivering strong adhesion and high tensile strength at the interfaces between the active material powders, conductive carbon black powders and the current collector foils. (ii) The binder should stay physically and chemically stable after being immersed in the electrolyte, such as EC, propylene carbonate and dimethyl carbonate, etc. (iii) The binder for cathode materials should possess wide electrochemical stability window up to $4.5 \mathrm{~V}$ (vs. $\mathrm{Li}^{+} / \mathrm{Li}$ ) avoiding electrochemical oxidation when charged up to the cut-off voltage limit. Similarly, the binder for the anode materials should have enough electrochemical reduction stability at low potential around $0 \mathrm{~V}$ (vs. $\mathrm{Li}^{+} / \mathrm{Li}$ ). (iv) The binder cannot cause adverse effect on the impedance of the electron and $\mathrm{Li}^{+}$diffusion for the electrode reaction. (v) The binder should be well dissolved or dispersed in the slurry and result in uniform distribution of both active materials and conductive carbon black. (vi) The binder and its utilization should be cost-effective, environmental-friendly and safe.

According to the interaction between the binders and the active powders, the binders can be divided into three types, i.e. dot-to-surface contact, segment-to-surface contact and network-to-surface contact, which are illustrated in Fig. 8 [73]. The dot-to-surface contact binders comprise of the emulsion binders such as polytetrafluoroethene (PTFE) latex, styrene-butadiene-rubber (SBR) latex and polyacrylates latex. After mixing, coating and drying, these latex particles stick to the surface of the active particles and bind them together by point connection, which usually leads to weak adherence. The segment-to-surface contact binders include most of the polymer solution binders such as PVDF, carboxymethyl cellulose (CMC), polyacrylic acid (PAA), polyvinyl alcohol, polyacrylate and polyacrylonitrile etc. After drying, the polymer chain segments adhere onto the surface of the active particles resulting in moderate adherence. The network-to-surface contact binders are characteristic of three-dimensional (3D) networks formed after coating via a thermal treatment or chemical reaction. Although 3D network causes strong adherence, the fabrication is complicated and the electrode sheets lack of flexibility. In regard to solvents, the binders can also be classified into two categories, organic solvent-based (nonaqueous) binders and water-based (aqueous) binders [74]. The non-aqueous binders are relatively expensive and harmful to environment because of using a large amount of organic solvent. Considering environmental benignity and cost-effectiveness, the aqueous binders have been attracted increasing attention $[75,76]$.

Among all the synthetic binders originating from the fossil oil, PVDF (as shown in Fig. 9) possesses superior electrochemical stability and are commercially used as binder for LIB electrode fabrication [77-79]. However, there are still some drawbacks, which limit the extensive application of PVDF. Firstly, PVDF is high-priced due to complicated synthesis and expensive monomer. Secondly, the expensive and volatile $\mathrm{N}$-methyl-2-pyrrolidone has to be used as solvent to dissolve PVDF, which further raise the cost of the battery and pollute the environment as well. Thirdly, 

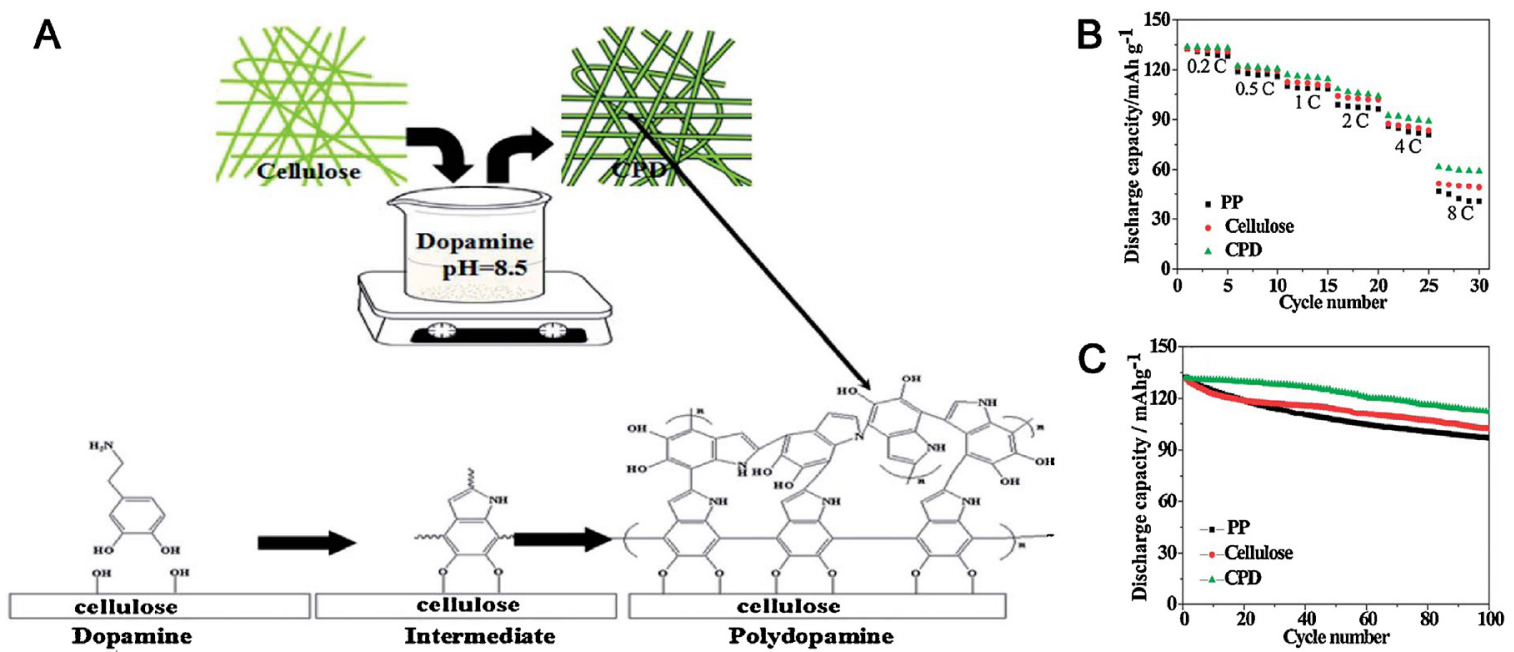

Fig. 7. A) Schematic illustration of the fabrication of cellulose/polydopamine (CPD) membrane, and the coating mechanism of polydopamine onto the surface of cellulose microfibers. (B) Comparison of rate capability of $\mathrm{LiCoO}_{2}$ /graphite cells assembled with CPD separator, cellulose separator, and PP separator. (C) Comparison of cycling performance of $\mathrm{LiCoO}_{2}$ /graphite cells assembled with CPD separator, cellulose separator, and PP separator [67]. Copyright 2014. Reproduced with permission from the Royal Society of Chemistry.

A

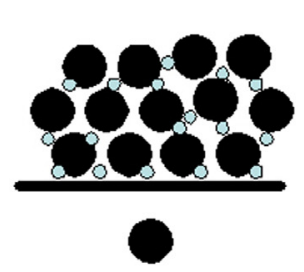

active particles
B

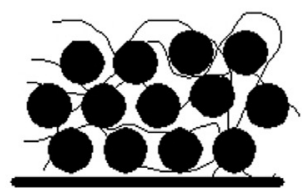

$\circ$

B latex particles

binder chains

C

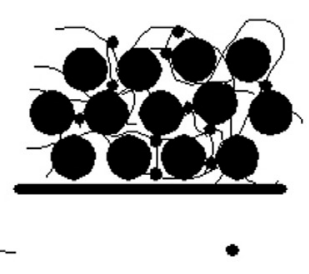

cross linkers

Fig. 8. Schematic illustration of the interactions between binders and active powders. (A) dot-to-surface contact, (B) segment-to-surface contact, and (C) network-to-surface contact.

PVDF solution is seriously sensitive to moisture in air which can deteriorate its viscosity. Finally, PVDF reacts with the lithium metal at elevated temperature which impairs the battery safety. Therefore, the development of greener, cheaper, and higher performance binders is of great importance today for battery technology.
The state-of-the-art LIBs composed of a transitional metal oxide cathode and a carbon-based anode can only deliver an energy density around $150 \mathrm{~W} \mathrm{~h} \mathrm{~kg}^{-1}$, which is far away from the requirement of EV for driving a distance of $200 \mathrm{~km}$ upon a single refuel. In order to meet the demand of $200 \mathrm{~km}$, the higher energy density rechargeable batteries

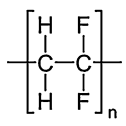

poly(vinylidene fluoride)

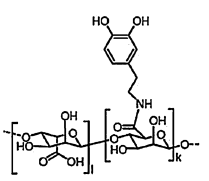

catechol-conjugated alginate

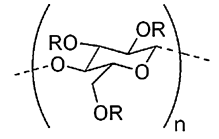

$\mathrm{R}=\mathrm{H}$ or $\mathrm{CH}_{2} \mathrm{CO}_{2} \mathrm{H}$

carboxymethyl cellulose

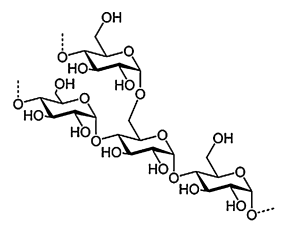

amylopectin

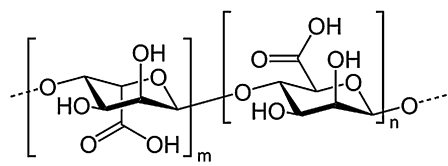

alginate

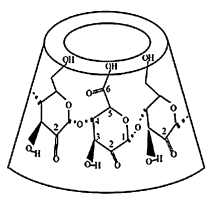

carbonyl- $\beta$-cyclodextrin

Fig. 9. Chemical structures of PVDF and some biomass-derived binders. 
Table 4

The comparison of typical synthetic binders and biomass-derived binders

\begin{tabular}{|c|c|c|c|c|c|}
\hline Binders & Applicable scope & Advantages & Disadvantages & Cost $\left(\$ \mathrm{~kg}^{-1}\right)$ & Ref. \\
\hline PVDF & $\begin{array}{l}\text { Cathode materials such as } \\
\mathrm{LiFePO}_{4}, \mathrm{LiCoO}_{2}, \mathrm{LiMn}_{2} \mathrm{O}_{4} \text {, } \\
\mathrm{LiNi}_{(1 / 3)} \mathrm{Co}_{(1 / 3)} \mathrm{Mn}_{(1 / 3)} \mathrm{O}_{2} \text {, etc. }\end{array}$ & $\begin{array}{l}\text { Chemical synthesis; superior } \\
\text { electrochemical stability }\end{array}$ & $\begin{array}{l}\text { Expensive; using organic } \\
\text { solvent; sensitive to moisture; } \\
\text { high ionic impedance }\end{array}$ & $20-30$ & [77-79] \\
\hline SBR & Graphite anode & $\begin{array}{l}\text { Chemical synthesis; sheap; } \\
\text { excellent elasticity; } \\
\text { environmental-friendly }\end{array}$ & $\begin{array}{l}\text { Poor chemical stability; low } \\
\text { electrochemical stability; }\end{array}$ & $3-5$ & {$[80-84]$} \\
\hline CMC-Na & $\begin{array}{l}\text { Graphite anode } \\
\mathrm{Si}, \mathrm{Sn} \text { or Ge based anodes } \\
\mathrm{LiFePO}_{4} \text { cathode }\end{array}$ & $\begin{array}{l}\text { Carboxylmethylation from } \\
\text { cellulose; cheap; } \\
\text { environmental-friendly; high } \\
\text { viscous and less dosage; low } \\
\text { ionic impedance; stiffness } \\
\text { (good to Si based anode) }\end{array}$ & $\begin{array}{l}\text { Stiff and poor flexibility; } \\
\text { variable chemical structure; } \\
\text { variable slurry viscosity }\end{array}$ & $2-5$ & {$[85-91]$} \\
\hline Alginate-Na & $\mathrm{Si}, \mathrm{Sn}$ or Ge based anodes & $\begin{array}{l}\text { Extracted from aquatic brown } \\
\text { algae; moderate price; } \\
\text { carboxyl group evenly } \\
\text { distribution; lower ionic } \\
\text { impedance; high stiffness in } \\
\text { electrolyte }\end{array}$ & $\begin{array}{l}\text { Variable M and G-blocks; } \\
\text { variable slurry viscosity; }\end{array}$ & $10-14$ & [93] \\
\hline $\begin{array}{l}\text { Alginate (catechol- } \\
\text { conjugated) }\end{array}$ & Si based anodes & $\begin{array}{l}\text { Catechol conjugated alginate; } \\
\text { strong adherence; } \\
\text { wetness-resistant adhesion }\end{array}$ & $\begin{array}{l}\text { Complicated synthesis; low } \\
\text { substitution }\end{array}$ & $>10$ & {$[98]$} \\
\hline$\beta-C D$ & $\begin{array}{l}\text { Sulfur based cathode, Si based } \\
\text { anodes }\end{array}$ & $\begin{array}{l}\text { Produced from starch by means } \\
\text { of enzymatic conversion; } \\
\text { cheap; environmental-friendly }\end{array}$ & Low viscosity & $3-4$ & {$[99,100]$} \\
\hline Amylopectin & Si, Sn and Ge based anodes & $\begin{array}{l}\text { Obtained from starch; cheap; } \\
\text { environmental-friendly }\end{array}$ & $\begin{array}{l}\text { Easy to degrade; variable } \\
\text { molecular weight; variable } \\
\text { slurry viscosity; moderate } \\
\text { adherence }\end{array}$ & $5-7$ & [101] \\
\hline Gelatin & $\begin{array}{l}\text { Graphite anode, } \mathrm{LiMn}_{2} \mathrm{O}_{4} \\
\text { cathode, sulfur based cathode }\end{array}$ & $\begin{array}{l}\text { Obtained from various animal } \\
\text { by-products; moderate price; } \\
\text { SEI improvement }\end{array}$ & $\begin{array}{l}\text { Electrochemical instability; } \\
\text { Complicated Constituents; } \\
\text { pH-dependent viscosity }\end{array}$ & $7-10$ & [103-107] \\
\hline
\end{tabular}

(300 $\mathrm{W} \mathrm{hg}^{-1}$ ) are desirable and the silicon-based anode batteries and lithium sulfur (Li-S) batteries are expected to boost energy density even up to $300-500 \mathrm{Wh} \mathrm{kg}^{-1}$. However, the cycle lives of $\mathrm{Si}$ electrodes are very short due to their significant volume expansion by up to $400 \%$ upon full lithiation and the sulfur cathode also suffers serious sulfur dissolution problem. Some natural polymers or their derivatives, such as CMC, alginate, amylopectin, carbonyl$\beta$-cyclodextrin (C- $\beta-C D)$ and gelatin have been recently explored to serve as robust and green binders to overcome the above mentioned defects of PVDF or huge volume expansion of the Si-based material or sulfur dissolution. The chemical structures of some typical biomass-derived binders are presented in Fig. 9, and the comparisons between the biomass-derived binders and PVDF as well as SBR are summarized in Table 4. The cells using these green binders typically exhibit high energy density, long cycle life, low cost, high safety, and environmental benignity compared to the conventional PVDF binder.

\subsection{Carboxymethyl cellulose-derived binder}

CMC is a cellulose derivative, and its backbone is made up by the coupling of carboxymethyl groups $\left(-\mathrm{CH}_{2}-\mathrm{COOH}\right)$ to some of the hydroxyl groups of the glucopyranose monomers. It is nontoxic, and is generally considered to be hypoallergenic. CMC membranes possess a good stiffness and a small elongation at break (5-8\%). Its sodium salt, CMC-Na is well water-soluble and used as a viscosity modifier or thickener to stabilize emulsions in various products.
CMC-Na serves widely as the anode binders with lower fractions (usually 2-5 wt.\%). However, CMC-Na molecules lack enough elasticity and always blend with elastic SBR to improve the flexibility of the electrode sheets in LIBs [80-84].

The Si or Sn based anodes suffer from poor cycling stability owing to huge volume changes during charge/discharge when using flexible PVDF as a binder. Owing to its stiffness nature, CMC-Na was proved to be an excellent binder for improving cycling stability of $\mathrm{Si}$ or $\mathrm{Sn}$ based anodes $[85,86]$. It was further demonstrated that a self-healing process of the strong $\mathrm{Si}-\mathrm{CMC}$ hydrogen bonding is critical for superior performances during cycling. This understanding leads to the well designing of Si-based electrodes with capacity retention reaching $1000 \mathrm{~mA} \mathrm{~h}^{-1}$ of composite (i.e., full Si capacity) for at least 100 cycles and with a Coulombic efficiency close to $99.9 \%$ per cycle [87].

In order to improve CMC-Na binding performance, a noticeable work has been done by Choi et al. They presented a thermally cured interconnected network of PAA and CMC-Na as a novel binder for silicon-based electrodes with superior performance even at high temperature [88]. The cross-linked PAA-CMC binder presents excellent mechanical resistance to strain and even permanent deformation because of the 3D linked polymer chains. The adoption of cross-linked PAA-CMC binder can effectively mitigate the large volume expansion of silicon anodes upon lithium insertion compared to PVDF binder: the cross-linked PAA-CMC binder better accommodates the expansional strain of silicon and a volume expansion 

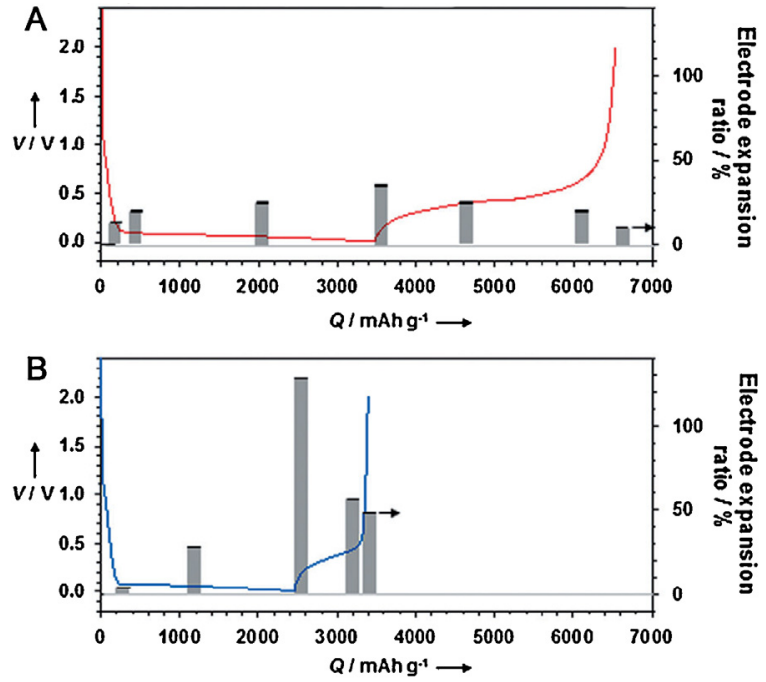

Fig. 10. Discharge-charge profiles of silicon composite electrodes with (A) cross-linked PAA-CMC binder (red line), and (B) PVDF binder (blue line) at $175 \mathrm{mAg}^{-1}$ between 0.005 and $2.0 \mathrm{~V}$ versus $\mathrm{Li} / \mathrm{Li}^{+}$. The black lines show the volume changes of electrodes during charging and discharging processes [88]. Copyright 2012. (For interpretation of the references to color in this figure legend, the reader is referred to the web version of the article.)

Reproduced with permission from WILEY-VCH Verlag GmbH \& Co., KGaA

of $35 \%$ in the fully lithiated state can be obtained (Fig. 10A), whereas the use of the PVDF binder leads to a drastically increased volume expansion of about $130 \%$ (Fig. 10B). Nanosized silicon powder with a 3D network as binder exhibits a high reversible capacity of capacity of $1600 \mathrm{~mA} \mathrm{~h} \mathrm{~g}^{-1}$ for a very high current density of $30 \mathrm{Ag}^{-1}$ at $60{ }^{\circ} \mathrm{C}$, which is much higher than those using the CMC-Na binder.

To date, only very limited investigations of the effects of CMC-Na on cathode materials have been carried out in comparison with different binders. Passerini recently reported that $\mathrm{CMC}$-based $\mathrm{LiFePO}_{4}$ electrodes dried at $170{ }^{\circ} \mathrm{C}$ were also able to display a capacity cycling retention of $75 \%$ for 1000 cycles [89], which corresponded to an overall capacity fading of only $0.025 \%$ per cycle. This is a support that CMC-Na might be electrochemically stable at positive potential over $3.6 \mathrm{~V}\left(\mathrm{vs}\right.$. $\mathrm{Li}^{+} / \mathrm{Li}$ ). It was also reported that the $\mathrm{LiNi}_{1 / 3} \mathrm{Mn}_{1 / 3} \mathrm{Co}_{1 / 3} \mathrm{O}_{2}$ electrode blended with $\mathrm{CMC}$ binder presented better cycling performance and rate capability than those with alginate and PVDF binders. Electrochemical impedance spectroscopy results indicated that the $\mathrm{LiNi}_{1 / 3} \mathrm{Mn}_{1 / 3} \mathrm{Co}_{1 / 3} \mathrm{O}_{2}$ electrode using $\mathrm{CMC}$ as binder had much lower charge transfer resistance and lower activation energy than the electrodes using alginate and PVDF as the binders [90,91]. Moreover, Li et al. studied the effects of the SBR/CMC blending ratio on the dispersion and the electrochemical properties of $\mathrm{LiCoO}_{2}$ electrodes. It was demonstrated that CMC-Na was highly efficient in dispersing $\mathrm{LiCoO}_{2}$, and SBR contributed to uniform dispersion of the CMC-Na binder and the flexibility of the electrode sheets after drying. This study revealed that the binder distribution had a significant influence on the electrical and electrochemical properties of the aqueous $\mathrm{LiCoO}_{2}$ electrodes than the dispersion of cathode powders did [92]. On the basis of the above-mentioned reports, it can be drawn a conclusion that the introduction of CMC-Na binder for cathode appears to be a very viable and promising solution to improve the overall electrode performance in a greener process.

\subsection{Alginate-derived binder}

Alginate contains a specific carboxylic group in each of the homopolymer's monomeric units (Fig. 9), which endows it a promising binder candidate especially for $\mathrm{Si}$ based anode. Recently, Yushin and his colleagues explored an alginate binder-based strategy to build Si anodes with improved performance characteristics for LIBs [93]. Compared with PVDF, the alginate binder, whatever in dry state or electrolyte solvent-impregnated wet state, shows much better mechanical properties. Importantly, when immersed into the electrolyte solvent, the stiffness of PVDF decays severely, whereas the stiffness of alginate does not change apparently (Fig. 11A-D). This strong stiffness of alginate is supposed to be of great benefit to the $\mathrm{Si}$ anode by alleviating the large changes in particle volume. Although CMC has a similar mechanical property with alginate (Fig. 11A, B, and E, F), there is a natural and much uniform distribution of carboxylic groups along the chain of alginate but not CMC, which is responsible for the better transport of $\mathrm{Li}^{+}$in the vicinity of $\mathrm{Si}$ nanopowders via hopping of $\mathrm{Li}^{+}$between the adjacent carboxylic cites, and the formation of a uniform and stable SEI layer on the Si surface, preventing degradation. Owing to the critical properties of alginate, the mixing Si nanopowder with alginate yielded a stable battery anode possessing a reversible capacity of $1200 \mathrm{~mA} \mathrm{~h}^{-1}$ for more than 1300 cycles (Fig. 12A), which was eight times higher than that of graphitic anodes. The reversible capacity of the cell for 100th cycles was also much higher than those using the PVDF and CMC binders (Fig. 12B) [93].

The investigations of mussel-inspired adhesive materials have revealed that the catechol group plays a decisive role in the exceptional wetness-resistant adhesion [62,94-97], which could be also very useful for improving binders' properties in battery because of the contact mode of each battery components in organic solvents. In 2013, Park et al. synthesized the catechol-conjugated alginate (3.4\% $\pm 0.4 \%$ substitution) (Fig. 9) and discovered that the interaction between the $\mathrm{Si}$ and catechol-conjugated alginate is double than that without catechol conjugation on a single-molecule level via atomic force microscopy pulling tests (Fig. 13A). The Si electrodes with catechol-conjugated alginate have good electrochemical stability and structural integrity, the enhanced film adhesion between $\mathrm{Si}$ and catechol-conjugated alginate can significantly improve the capacities and cycle performance of Si-based anodes (Fig. 13B). More importantly, since the wetness-resistant catecholic adhesion works availably with various substrates, this mussel-inspired catechol-conjugated alginate binder has potential applications in other LIB electrodes that suffer similar volume changes as Si during cycling [98]. 

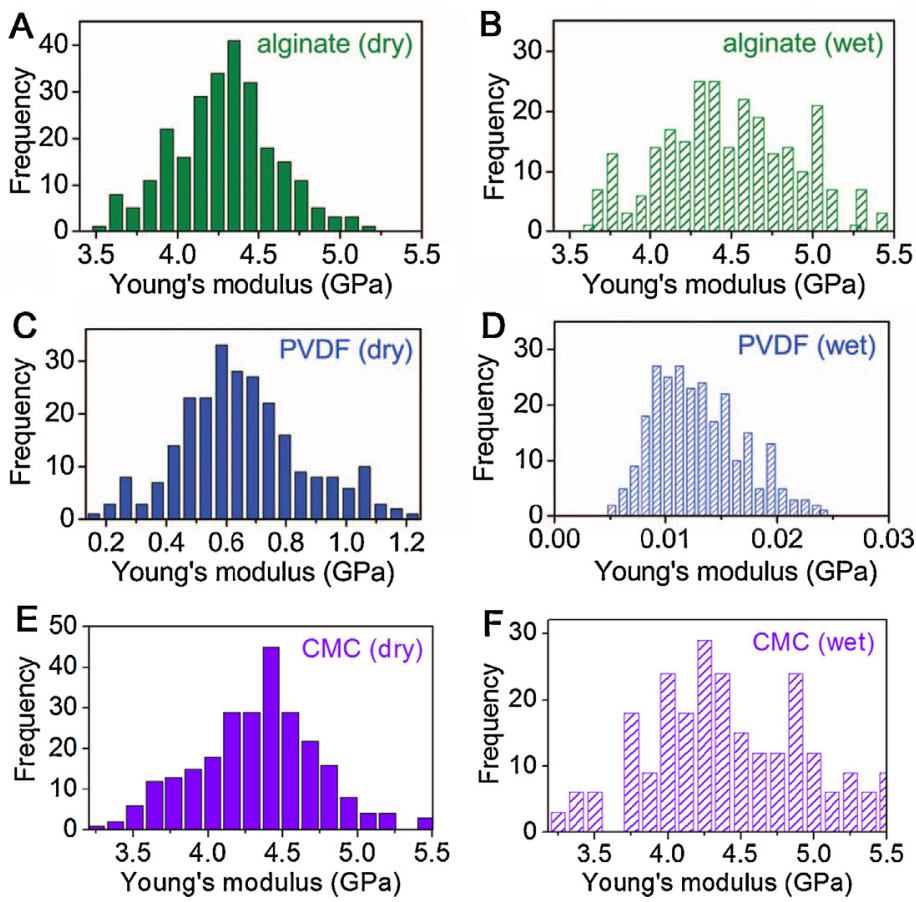

Fig. 11. Atomic force microscopy indentation studies showing the Young's modulus comparison between the Na alginate (A, B), PVDF (C, D), and CMC (E, F) in both dry state and electrolyte solvent-impregnated wet state [93].

Copyright 2011. Reproduced with permission from the American Association for the Advancement of Science.
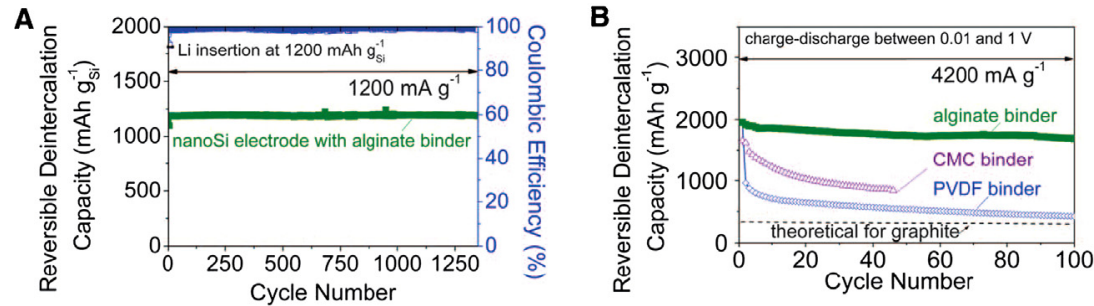

Fig. 12. (A) Reversible Li-extraction capacity and Coulombic efficiency of the alginate binder-based nano-Si electrodes versus cycle number for Li insertion level fixed to $1200 \mathrm{~mA} \mathrm{~h}^{-1} \mathrm{Si}$. (B) Reversible Li-extraction capacity of nano-Si electrodes with alginate, CMC, and PVDF binders versus cycle number at $4200 \mathrm{~mA} \mathrm{~g}^{-1}$ between 0.01 and $1 \mathrm{~V}$ versus $\mathrm{Li} / \mathrm{Li}^{+}$[93].

Copyright 2011. Reproduced with permission from the American Association for the Advancement of Science.
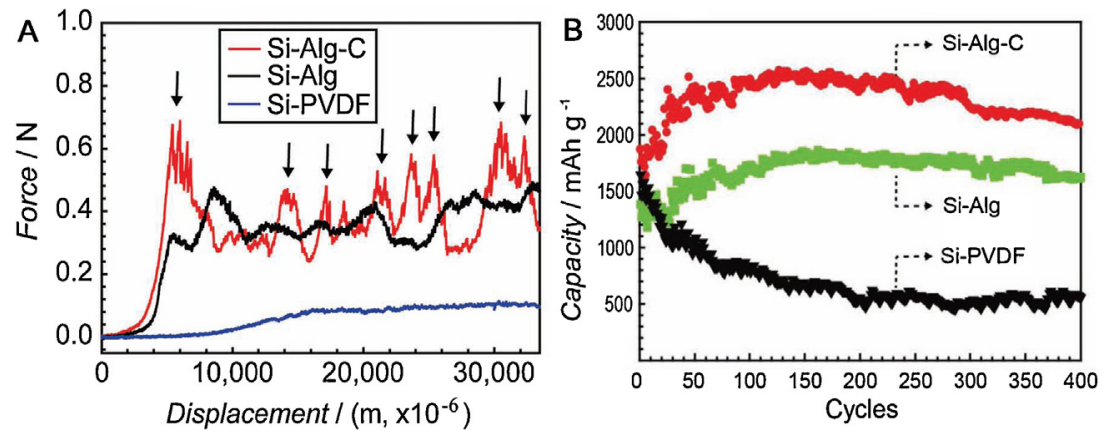

Fig. 13. (A) Atomic force microscopy force-distance curves and (B) the cycling performance at a C/2 rate ( $\left.2100 \mathrm{mAg}^{-1}\right)$ of the $\mathrm{Si}$ electrodes with catecholconjugated alginate (Alg-C), alginate (Alg), and PVDF binders, indicating that the better film adhesion caused by Alg-C leads to the better cycle performance [98].

Copyright 2013. Reproduced with permission from WILEY-VCH Verlag GmbH \& Co., KGaA. 


\section{3. $\beta$-cyclodextrin-derived binder}

$\beta-C D$ is a 7 -membered sugar ring molecule incorporating $\mathrm{D}(+)$-glucose monomeric units linked by $\alpha(1 \rightarrow 4)$ linkages, and it can be easily obtained from ordinary starch by the well-established enzymatic hydrolysis method. The limited water solubility $\left(1.85 \mathrm{~g}\right.$ in $100 \mathrm{~g} \mathrm{H}_{2} \mathrm{O}$ at $25^{\circ} \mathrm{C}$ ) of $\beta$ $\mathrm{CD}$ restricts its application as aqueous binder in batteries; however via simple chemical modification or polymerization one can realize the potential application of $\beta-C D$ derivatives as binders in rechargeable Li batteries $[99,100]$.

By the partial carbonylation of hydroxyl groups of $\beta-C D$ with $\mathrm{H}_{2} \mathrm{O}_{2}$, Wang and his colleagues synthesized $C-\beta-C D$, which has a much better water solubility than $\beta-C D$ and exhibits a strong bonding capability and electrochemical stability. When $C-\beta-C D$ was utilized as a binder for sulfur-based cathodes, the high solubility and strong bonding make $C-\beta-C D$ forms a mechanically strong gel film around the surface of the sulfur composite, which can effectively suppress the aggregation of the sulfur composite and reduce the dissolution of soluble polysulfide. As a result, satisfied electrochemical performances, including a high reversible capacity of $694.2 \mathrm{mAh}_{\text {(composite) }^{-1}}$ and $1542.7 \mathrm{~mA} \mathrm{~h}_{\text {(sulfur) }}{ }^{-1}$, a high sulfur utilization (92.2\%) and a much improved cycle performance (Fig. 14A), were achieved for the sulfur-based composite using $C-\beta-C D$ as the binder [99]. Very recently, Choi and his colleagues reported a polymerized $\beta-C D\left(\beta-C D_{p}\right)$ as an effective multidimensional binder for Si nanoparticle anodes in lithium batteries to mitigate the severe capacity fading caused by unparalleled volume change of Si during cycling [100]. In this work, hyperbranched $\beta-C D_{p}$ network structure, which incorporated a series of hydroxyl and ether groups, was obtained from the reaction between $\beta-C D$ and epichlorohydrin under strong basic conditions. Compared against other conventional linear binders, multidimensional noncovalent contacts between $\beta-\mathrm{CD}_{\mathrm{p}}$ and $\mathrm{Si}$ particles come into being, which can provide superior mechanical strength against the volume expansion of $\mathrm{Si}$ and also create a self-healing effect. Owing to the above advantages, $\beta-C D_{p}-$ based $\mathrm{Si}$ electrode presented significantly improved cycle performance (Fig. 14B), and the cycle performance can be further improved by the $\beta-\mathrm{CD}_{\mathrm{p}} /$ alginate hybrid binder in a synergistic effect [100]. Considering its low cost, environmental benignity and easy manipulation of modification (or polymerization), $\beta$-CD becomes a very attractive binder candidate for practical adoption in rechargeable lithium battery manufacturing processes.

\subsection{Amylopectin-derived binder}

Amylopectin, one of the most common polysaccharides, is a major component of starch produced by plants. As a branched polymer of glucose, the linear chains of amylopectin are linked with $\alpha(1 \rightarrow 4)$ glycosidic bonds, and branching occur every 24-30 glucose units with $\alpha(1 \rightarrow 6)$ glycosidic linkages (Fig. 9). Recently, Komaba et al. explored amylopectin as binder for Si-based electrodes, which exhibited significantly higher capacity and better cycle performance (the capacity remains at $\sim 800 \mathrm{~mA} \mathrm{~h}^{-1}$ over 150 cycles,) in LIBs compared with PVDF binder. The improved performance of amylopectin binder is probably related to the degree of branching [101]. However, the inferior adhesion ability resulting from the hydroxyl groups and the relatively higher price of amylopectin might hamper its extensive application as a sustainable binder.

\subsection{Gelatin-derived binder}

Gelatin is a translucent, colorless and flavorless solid substance, produced by partial hydrolysis of collagen obtained from various animal by-products, and is usually classified as a foodstuff. As a mixture of peptides and proteins, gelatin possesses a plenty of amino and carboxyl groups, which might entail superior binder properties, e.g. good adhesion and fast ion diffusion. It was reported by Gaberšček et al. that, gelatin has been successfully applied as a green binder for the graphite anodes [102,103] and $\mathrm{LiMn}_{2} \mathrm{O}_{4}$ cathodes $[104,105]$. The gelatin binder could mitigate the irreversible initial capacity loss of graphite anode because it could contribute to SEI formation. The gelatin binder could also be beneficial for the uniform distribution of conductive carbon black particles and improved the capacity and cycling stability of $\mathrm{LiMn}_{2} \mathrm{O}_{4}$ cathode. Gelatin was also successfully used as a new binder of the sulfur cathode in Li-S batteries [106]. For the sulfur cathode, it is demonstrated that gelatin not only functions as an effective adhesive agent and dispersion agent, but also enhances the redox reversibility by slowing down the reducing reaction of elemental sulfur during the discharging process and reforming S8 after the charging process [107]. The drawback of the gelatin binder is lower electrochemical stability originating from the complicated chemical constituents and chemically instable groups in gelatin, which hampers its real application in lithium batteries.

\section{Biomass-derived electrode materials}

Current electrochemical energy devices mainly depend on the substantive use of electrode materials that are far from renewable and sustainable, e.g. inorganic compounds, which often require rare metals [4-7]. To merit the requirements of a resource-conserving, environment-friendly society, it remains great challenges and significances to pursuit renewable and sustainable electrode materials. Owing to their intrinsic properties and advantages, including the environment-friendly characteristics, the diverse structures, the intrinsic mechanical strength and flexibility, as well as the capability to efficiently accommodate other functional materials or liquid electrolyte, the renewable biomass and their derivatives have been spontaneously considered as the possible alternatives to replace the traditional non-sustainable electrode materials. In the past decade, some significant efforts have been put into developing sustainable and high-performance biomass-derived electrode materials: (1) The most broad research avenue is to apply biomass-derived nanostructures as renewable and favorable electrode materials in the advanced energy storage devices [13-15]. In order to be applied as electrode material, various electrochemically functional materials (e.g. conductive polymers, advanced carbon nanomaterials, etc.) have been integrated to endow cellulose composite 

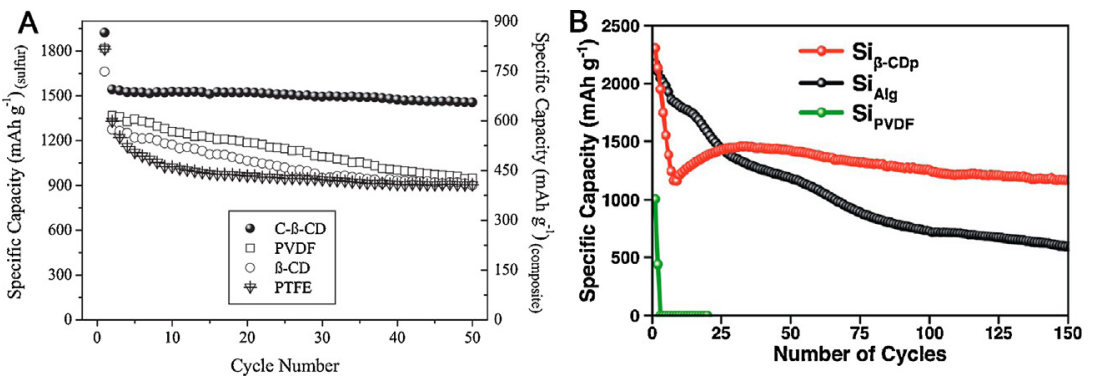

Fig. 14. (A) Cycle performance of sulfur-based cathodes with $\beta-C D, C-\beta-C D$, PVDF, and PTFE binders at 0.2 C [99]. Copyright 2013. Reproduced with permission from WILEY-VCH Verlag GmbH \& Co., KGaA. (B) Cycle performance of Si-based cathodes with $\beta-\mathrm{CD}_{\mathrm{p}}$, alginate, and PVDF binders at $1 \mathrm{C}$ (4200 mA g ${ }^{-1}$ ) [100]. Copyright 2014. Reproduced with permission from the American Chemical Society.

with good electrical conductivity and electrochemical function. These conducting materials can be introduced into hierarchical biomass at different scales, from chemical modification of a biomass polymer at molecular scale to composite formation at nanofibrillated/microfibrillated fiber scale to surface coating onto biomass-based paper. (2) The other interesting and challenging research avenue is to facilely synthesize electroactive molecules from renewable natural biomass precursors via modern green chemistry concepts and then apply them as sustainable electrode materials [1].

In this section, we will present recent progress in the development of biomass derived electrode materials and their applications in energy storage. Although many works report the significant applications of pyrolyzed carbon, derived from diverse biomass, as electrode materials [108-115], considering the subversive transformation of biomass, the related progress is not involved in this review.

\subsection{Conducting polymer/biomass composites as electrode materials}

Conducting polymers, such as polypyrrole (PPy), polyaniline (PANI), polythiophene and poly (ethylenedioxythiophene), are organic polymers that are able to conduct electrons and ions [116]. The characteristics of conducting polymers, including distinguished electrochemical and mechanical properties, low cost, ease of processability, convenient modification of the chemical structures, and relatively light weight, allow them (typically PPy and PANI) to be used as attractive electrodes in electrochemical capacitors and LIBs [117,118]. However, conductive polymers suffer from low capacity since redox processes usually only occur at the surface of conducting polymer films due to limited accessibility. Thus, conducting polymers are commonly deposited onto some substrates, in which the porous and less expensive substrates are desirable [119-123]. Interestingly, the distinguished characteristics of biomass endow them as great candidates to modify the electrochemical and mechanical properties of the brittle conducting polymers. Biomass/conducting polymer composites can be molded in different shapes to obtain conductive paper material which can be either directly used as a working electrode or function as an underlying conductive substrate material for deposition of various metals or metal oxides [13,124].

\subsubsection{Polypyrrole/biomass composites}

$\mathrm{PPy}$, one typical conductive polymer, shows promise but too inefficient for practical electrochemical energy storage applications, probably due to the inaccessibility and the thick and dense layers of the PPy material used [125]. Early in 1980s, the electrically conducting PPy/methylcellulose composite has been synthesized to improve the mechanical properties of PPy, which finally presented a maximum conductivity of $0.2 \mathrm{~S} \mathrm{~cm}^{-1}$ [126]. In recent years, despite extensive efforts to develop new cellulose-based electrodes for battery applications, there is no satisfactory charging performance to be obtained until in 2009 by one group at Uppsala University [127]. Strømme and colleagues firstly developed a novel nanostructured high-surface area electrode material of Cladophora nanocellulose coated with a $50 \mathrm{~nm}$ layer of PPy (Fig. 15A and B), which exhibited an exceptionally high ion-exchange capacity [128], and then they explored the possibilities of utilizing these composite electrode materials for energy storage in paper-based batteries (Fig. 15C and D) [127]. Cladophora algae cellulose has a unique nanostructure, entirely different from that of terrestrial plants, and the possibility of energy-storage applications was raised in view of its large surface area $\left(80 \mathrm{~m}^{2} \mathrm{~g}^{-1}\right)$. Batteries based on this prepared conductive paper composite material can be charged with currents up to $600 \mathrm{~mA} \mathrm{~cm}^{-2}$, with only a loss of $6 \%$ after 100 charging cycles. The aqueous-based batteries entirely based on cellulose and PPy, also exhibited high charge capacities (between 25 and $33 \mathrm{~mA} \mathrm{hg}^{-1}$ ). It was demonstrated that the extreme thinness of the PPy layer coated on Cladophora algae cellulose played a critical role in obtaining a much higher charge capacity than the previous batteries based on advanced polymers.

After their original work, Strømme and colleagues continued to complete some substantial works in this area. They reinforced the composites of PPy/Cladophora nanocellulose with $8 \mu \mathrm{m}$-thick chopped carbon filaments (Fig. 16). It suggests that the nonelectroactive carbon filaments can decrease the contact resistances and the resistance of the reduced cellulose/PPy composite. The obtained paper-based energy-storage devices by using the reinforced composites as electrode materials show enhanced capacitances and cycle performance (Table 5) [129]. Then, they detailedly investigated how different postsynthesis treatments (e.g. polymerization conditions, rinsing, and storage) affected both the short-term and the 

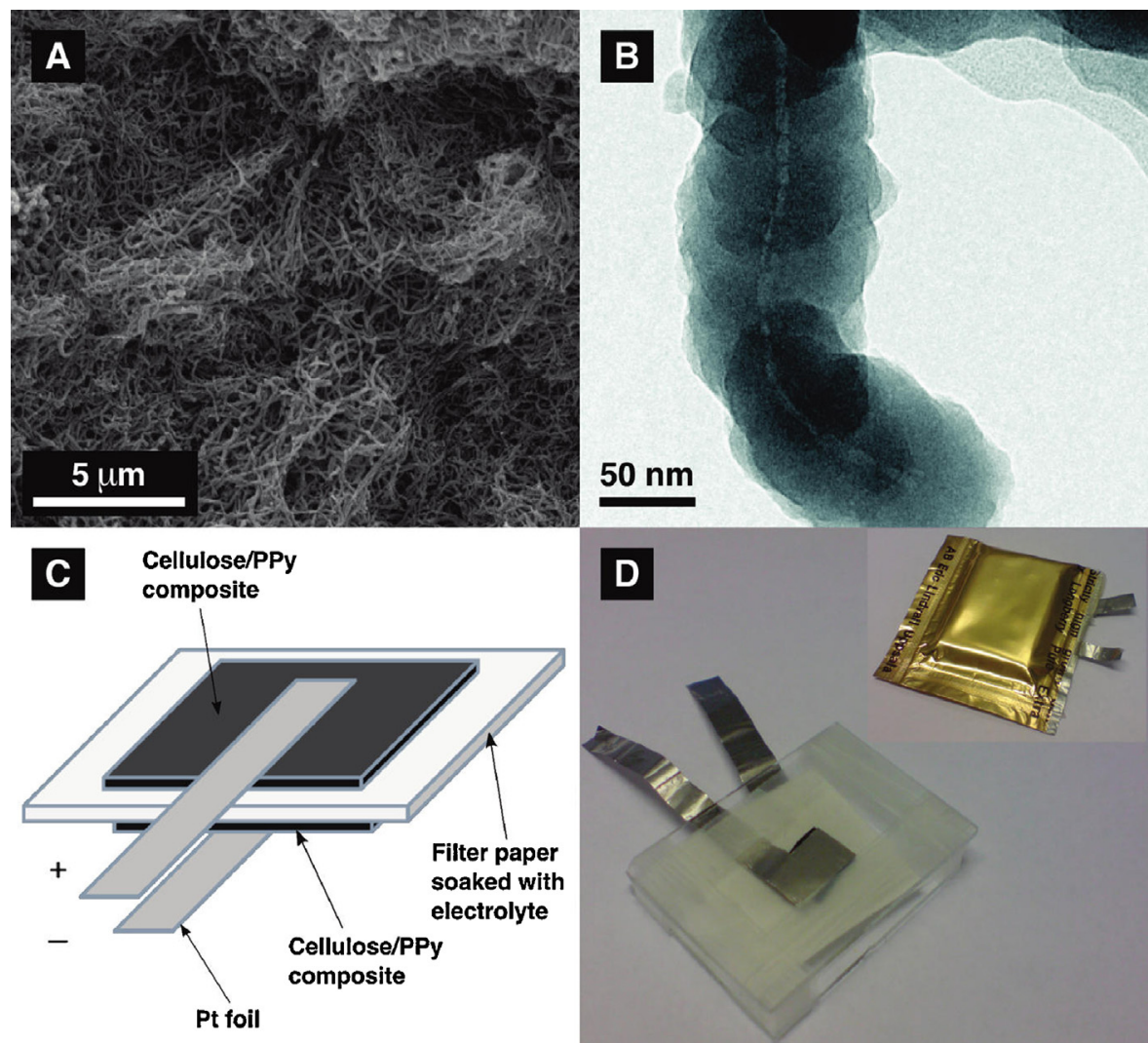

Fig. 15. SEM (A) and TEM (B) images of the PPy/Cladophora cellulose composite fiber. Schematic (C) and photograph (D) of the PPy/Cladophora cellulose composite paper-based battery cell [127].

Copyright 2009. Reproduced with permission from the American Chemical Society.

long-term properties (in terms of purity, chemical composition, conductivity, and electroactivity) of the Cladophora nanocellulose/PPy composite [130]. They also demonstrated that it was possible to coat the individual fibers of wood-based nanocellulose with PPy using in situ chemical polymerization. The obtained dry composite exhibits an even better capacity performance than that of Cladophora nanocellulose/PPy composite (Table 5) [131].

In addition to Cladophora cellulose and land plant cellulose, other kinds of cellulose, e.g. bacterial cellulose and cotton cellulose [132,133], can also be adopted to prepare high-performance cellulose/conducting polymer composites. The core/sheath structured conductive nanocomposites were prepared by wrapping a homogenous layer of PPy around bacterial CNFs (produced by Acetobacter xylinum) via in situ polymerization. By optimizing reaction protocols, the ordered core/sheath bacterial CNFs/PPy nanostructure achieved an outstanding electrical conductivity as high as $77 \mathrm{~S} \mathrm{~cm}^{-1}$, and demonstrated promising potential for supercapacitors, with a highest mass specific capacitance hitting $316 \mathrm{Fg}^{-1}$ at $0.2 \mathrm{Ag}^{-1}$ current density (Table 5) [132]. Porous nanocomposites consisting of cotton cellulose nanocrystals and PPy were fabricated using electrochemical co-deposition. The obtained nanocomposite presented a high capacitance of $256 \mathrm{Fg}^{-1}$ and a good stability, which were comparable to that of a PPy/carbon nanotubes (CNTs) composite deposited under the same conditions [133]. Significantly,

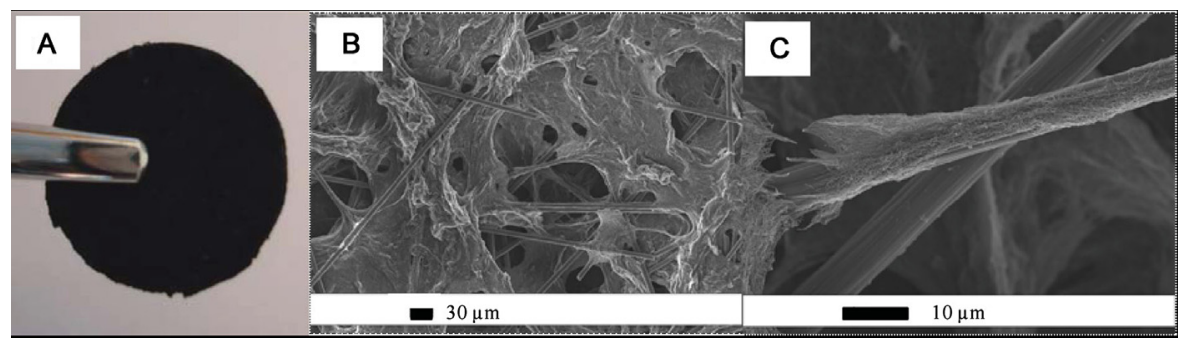

Fig. 16. Photograph (A) and SEM images (B, C) of PPy/Cladophora cellulose composite sample reinforced with $8 \mu \mathrm{m}$-thick chopped carbon filaments [129]. Copyright 2012. Reproduced with permission from WILEY-VCH Verlag GmbH \& Co., KGaA 
Table 5

Literature data on biomass/conducting polymer composites-based electrodes for supercapacitor or battery applications.

\begin{tabular}{|c|c|c|c|c|c|}
\hline Electrodes & Preparation & $\begin{array}{l}\text { Conductivity } \\
\left(\mathrm{S} \mathrm{cm}^{-1}\right)\end{array}$ & $\begin{array}{l}\text { Device performance: capacity } \\
\left(\mathrm{Fg}^{-1}\right) \text { or capacitance }\left(\mathrm{mA} \mathrm{h}^{-1}\right) \text { or } \\
\text { energy density }\left(\mathrm{Wh} \mathrm{kg}^{-1}\right) \text { or } \\
\text { power density }\left(\mathrm{kW} \mathrm{kg}^{-1}\right)\end{array}$ & Remarks & Ref. \\
\hline $\begin{array}{l}\text { Nanocellulose/PPy } \\
\text { conductive paper } \\
\text { composite }\end{array}$ & $\begin{array}{l}\text { In situ chemical } \\
\text { polymerization }\end{array}$ & $>1 \mathrm{~S} \mathrm{~cm}^{-1}$ & $\begin{array}{l}25 \mathrm{mAhg}^{-1} \text { at } 10 \mathrm{~mA} \\
33 \mathrm{mAhg}^{-1} \text { at } 320 \mathrm{~mA}\end{array}$ & $\begin{array}{l}\text { PPy layer }(50 \mathrm{~nm} \text { in } \\
\text { thickness) was coated } \\
\text { on Cladophora algae } \\
\text { cellulose }\end{array}$ & [127] \\
\hline $\begin{array}{l}\text { Nanocellulose/PPy/carbon } \\
\text { filaments conducting } \\
\text { composite }\end{array}$ & $\begin{array}{l}\text { In situ chemical } \\
\text { polymerization } \\
\text { followed by } \\
\text { acid-washed }\end{array}$ & 1 & $\begin{array}{l}77 \mathrm{~mA} \mathrm{~h} \mathrm{~g}^{-1} \\
\sim 60-70 \mathrm{Fg}^{-1} \\
1.75 \mathrm{~W} \mathrm{~h} \mathrm{~kg}^{-1} \\
2.7 \mathrm{~kW} \mathrm{~kg}^{-1}\end{array}$ & $\begin{array}{l}8 \mu \mathrm{m} \text {-thick chopped } \\
\text { carbon filament was } \\
\text { used to strength the } \\
\text { nanocellulose/PPy } \\
\text { composite }\end{array}$ & [129] \\
\hline $\begin{array}{l}\text { Nanocellulose/PPy } \\
\text { conducting composite }\end{array}$ & $\begin{array}{l}\text { In situ chemical } \\
\text { polymerization }\end{array}$ & $\sim 1.5 \mathrm{~S} \mathrm{~cm}^{-1}$ & $80 \mathrm{mAhg}^{-1}$ & $\begin{array}{l}\text { Wood-based } \\
\text { nanocellulose was used }\end{array}$ & [131] \\
\hline $\begin{array}{l}\text { Nanocellulose/PPy } \\
\text { core/sheath structured } \\
\text { conductive } \\
\text { nanocomposite }\end{array}$ & $\begin{array}{l}\text { In situ chemical } \\
\text { polymerization of } \\
\text { self-assembled pyrrole }\end{array}$ & $77 \mathrm{~S} \mathrm{~cm}^{-1}$ & $316 \mathrm{Fg}^{-1}$ at $0.2 \mathrm{Ag}^{-1}$ & $\begin{array}{l}\text { Bacterial cellulose } \\
\text { produced by } \\
\text { Acetobacter xylinum } \\
\text { was used }\end{array}$ & [132] \\
\hline $\begin{array}{l}\text { Cellulose/PPy conductive } \\
\text { nanocomposite }\end{array}$ & $\begin{array}{l}\text { Electrochemical } \\
\text { co-deposition }\end{array}$ & 1 & $256 \mathrm{Fg}^{-1}$ & $\begin{array}{l}\text { Cotton extracted } \\
\text { cellulose nanocrystals } \\
\text { were used }\end{array}$ & [133] \\
\hline $\begin{array}{l}\text { Printing paper/PPy } \\
\text { composite }\end{array}$ & $\begin{array}{l}\text { "Soak and } \\
\text { polymerization" } \\
\text { method }\end{array}$ & $15 \mathrm{~S} \mathrm{~cm}^{-1}$ & $\begin{array}{l}0.42 \mathrm{~F} \mathrm{~cm}^{-2} \\
1 \mathrm{~mW} \mathrm{~h} \mathrm{~cm}^{-3} \\
0.27 \mathrm{~W} \mathrm{~cm}^{-3}\end{array}$ & $\begin{array}{l}\text { Common printing } \\
\text { paper was used }\end{array}$ & [134] \\
\hline Cellulose/PPy composites & $\begin{array}{l}\text { Chemical } \\
\text { polymerization } \\
\text { followed by } \\
\text { electropolymerization }\end{array}$ & 1 & $250 \mathrm{Cg}^{-1}$ (charge capacity) & $\begin{array}{l}\text { PPy was doped with } \\
\text { anthraquinone-2,6- } \\
\text { disulfonic } \\
\text { acid }\end{array}$ & [135] \\
\hline $\begin{array}{l}\text { Lignin/PPy } \\
\text { interpenetrating } \\
\text { networks }\end{array}$ & $\begin{array}{l}\text { Electrochemical } \\
\text { polymerization of } \\
\text { pyrrole }\end{array}$ & $\sim 1 \mathrm{~S} \mathrm{~cm}^{-1}$ & $70-75 \mathrm{~mA} \mathrm{~h} \mathrm{~g}^{-1}$ & $\begin{array}{l}\text { Lignin derivatives from } \\
\text { the brown liquor (a } \\
\text { by-product from the } \\
\text { manufacture of paper } \\
\text { pulp) was used }\end{array}$ & [136] \\
\hline $\begin{array}{l}\text { CNFs/PANI } \\
\text { nanocomposites }\end{array}$ & $\begin{array}{l}\text { In situ polymerization } \\
\text { of aniline onto } \\
\text { bacterial CNFs }\end{array}$ & $5.1 \mathrm{Scm}^{-1}$ & $273 \mathrm{Fg}^{-1}$ at $0.2 \mathrm{Ag}^{-1}$ & $\begin{array}{l}\text { Bacterial CNFs was } \\
\text { used }\end{array}$ & [144] \\
\hline CMC/PANI nanorods & $\begin{array}{l}\text { Via one-step in situ } \\
\text { oxidation } \\
\text { polymerization }\end{array}$ & 1 & $451.25 \mathrm{Fg}^{-1}$ & $\begin{array}{l}\text { Commercial CMC was } \\
\text { used }\end{array}$ & [145] \\
\hline CNFs/Ag/PANI aerogel & $\begin{array}{l}\text { Electrodeposition of } \\
\text { PANI onto } \mathrm{Ag} / \mathrm{CNFs}\end{array}$ & $\begin{array}{l}1 \Omega \mathrm{sq}^{-1} \text { (for } \\
\mathrm{CNF} / \mathrm{Ag} \text { aerogel) }\end{array}$ & $176 \mathrm{mFcm}^{-2}$ at $10 \mathrm{mV} \mathrm{s}^{-1}$ & $\begin{array}{l}\text { Bleached kraft } \\
\text { softwood pulp-derived } \\
\text { CNFs was used }\end{array}$ & [146] \\
\hline
\end{tabular}

not only CNFs directly derived from natural organisms have been used, some cellulose products, such as commercialized printing paper, have also been demonstrated to be very suitable materials to fabricate biomass/conjugated polymer composite electrodes for electrochemical devices. Very recently, Zhou and colleagues reported a highly conductive paper fabricated through PPy coating on common printing paper, which shows a high electrical conductivity and good electrochemical performance as electrode material [134]. To further enhance the charge storage capacity of cellulose/PPy composites, the chemical doping seems an alternative approach. The PPy/cellulose composites doped with anthraquinone-2,6-disulfonic acid via electropolymerization were prepared, which significantly increased the gravimetric charge capacity to $250 \mathrm{Cg}^{-1}$ due to the redox activities of PPy and the dopant [135].

Lignin is another abundant biomass in nature, and it has also been demonstrated to be efficient electrode material by forming lignin/conjugated polymer interpenetrating networks. Inspired by the fact that quinones usually play the role of soluble electron/proton transport agents in photosynthesis process and that lignin can be easily incorporated with large numbers of quinone sites from phenolic groups, Inganäs and colleagues created an inexpensive, electroactive conjugated polymer/biopolymer composite cathode by combining quinone electrochemistry and PPy conductivity [136]. The interpenetrating PPy/lignin composite film was electrochemically prepared from a mixture of pyrrole and lignin derivatives from the brown liquor, which is a by-product from the manufacture of paper pulp and is largely composed of lignosulfonate. The ligninderived quinone group was used for electron and proton storage and exchange during redox cycling, thus the charge storages of lignin and PPy in the PPy/lignin composite were combined. It can be seen that in the galvanostatic discharge curves for the PPy/lignin composite films, two slopes were observed, which should be ascribed to electrochemical activities of PPy and lignin-derived quinones respectively (Fig. 17). Especially for the thinner PPy/lignin composite film, it was a favorable diffusion situation, and the 

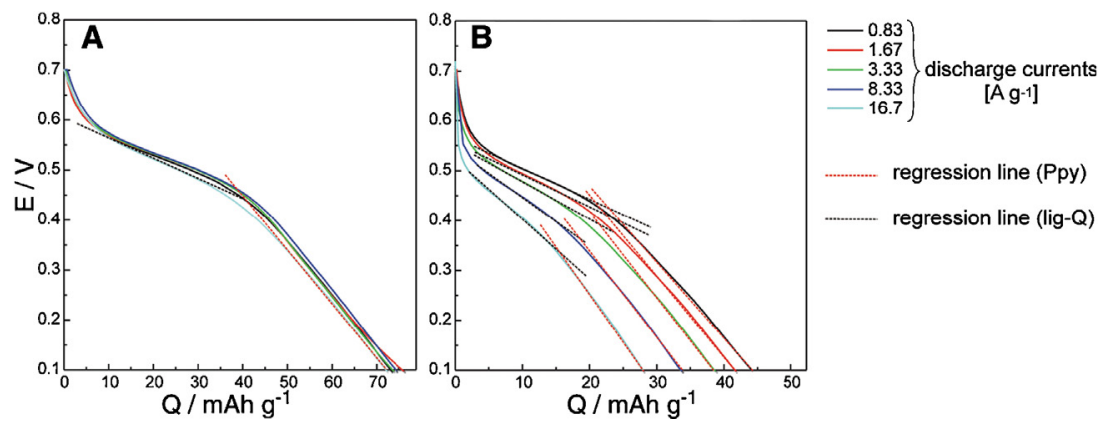

Fig. 17. Discharge curves under galvanostatic conditions in $0.1 \mathrm{M} \mathrm{HClO}_{4}$ for (A) thinner $(0.5 \mu \mathrm{m})$ and $\left.\mathrm{B}\right)$ thicker (1.9 $\left.\mu \mathrm{m}\right) \mathrm{PPy} / \mathrm{lignin}$ composite film, and the linear regression lines used for capacitance analysis [136].

Copyright 2012. Reproduced with permission from the American Association for the Advancement of Science.

capacities of lignin-derived quinones and PPy was calculated to be $\sim 40$ and $30-35 \mathrm{~mA} \mathrm{~h} \mathrm{~g}^{-1}$, respectively (Fig. 17A). Finally, reasonable charge densities between 70 and $75 \mathrm{~mA} \mathrm{~h} \mathrm{~g}^{-1}$ were realized for the prepared low-cost, green thin-film electrode [136].

\subsubsection{Polyaniline/biomass composites}

As another outstanding conducting polymer, PANI has a relatively high theoretical specific capacity $\left(964 \mathrm{Fg}^{-1}\right)$. However, PANI has common weaknesses with PPy, i.e. the limited achieved capacitance and the poor potential cycling stability $[125,137]$. Recent studies showed that, the fabrication and application of highly porous PANI-inorganic nanomaterial (CNTs, graphene, and metal oxides) composites were very effective to improve the capacitance and stability by facilitating ion and solvent movements [125,137-140]. Recently, biomass materials especially cellulose have also been explored as very promising scaffold materials for fabrication of PANI-based composites for energy storage applications [141-143]. Tang et al. prepared the bacterial CNFs-supported PANI nanocomposites with flake-shaped morphology via in situ polymerization of aniline onto bacterial CNFs scaffold, which presented a good electrical conductivity of $5.1 \mathrm{Scm}^{-1}$, and a high mass-specific capacitance of $273 \mathrm{~F} \mathrm{~g}^{-1}$ at $0.2 \mathrm{Ag}^{-1}$ in supercapacitor application [144]. Lei et al. prepared CMC/PANI nanorods with uniform diameters about $100 \mathrm{~nm}$, and obtained a specific capacitance as high as $451.25 \mathrm{Fg}^{-1}$ and a good cycle performance [145]. Very recently, Deng et al. showed that the incorporation of $\mathrm{Ag}$ nanoparticles into CNF/PANI composite can provide fast electron transportation channels to achieve high capacitance. The solid-state flexible supercapacitors based on the CNF/Ag/PANI aerogel can reach a high specific capacitance of $176 \mathrm{mF} \mathrm{cm}^{-2}$ at $10 \mathrm{mV} \mathrm{s}^{-1}$, and can remain the same electrochemical properties even under severe bending [146].

\subsection{Carbon nanomaterials/biomass composites as electrode materials}

Carbon materials are always playing a critical role in energy conversion and storage [147]. Due to their novel size-/surface-dependent electronic, optical, mechanical and thermal properties as well as catalytic properties, carbon nanomaterials, especially CNTs and graphenes, have been emerged as new class of electrode materials for the next generation electrochemical energy storages. Tremendous efforts have been made to develop carbon-based high-performance energy storage devices, and many great progresses have been achieved [9,148-150]. In the most recent development of flexible and versatile energy storage devices, various types of carbon nanomaterails/biomass composites have been explored as electrode materials, owing to the intrinsic characteristics of biomass materials. As systematically demonstrated, mesoporous cellulose fibers in these composite electrode not only functions as a substrate with large surface area but also acts as an interior electrolyte reservoir, where electrolyte can be absorbed much in the cellulose fibers and is ready to diffuse into an energy storage material [151].

\subsubsection{Carbon nanotubes/biomass composites}

CNTs are the most common carbon nanomaterials selected to form composite electrode with cellulose, due to their excellent properties, such as high conductivity, excellent electrochemical stability, low mass density, high mechanical strength, and high specific surface area. It is known that CNTs are particularly versatile in binding with cellulose. Ajayan and colleagues have developed a new nanocomposite paper energy storage technology which integrates the three basic components of an electrochemical storage device-electrode, separator and electrolyte-into single contiguous nanocomposite units that can serve as building blocks for thin, mechanically flexible electrochemical energy devices. Unmodified cellulose fibers were dissolved in a room-temperature ionic liquid (1-buty1,3methylimidazolium chloride ([bmIm][Cl]), and then the cellulose solution was then coated onto vertically grown multi-walled CNTs (MWCNTs) to form the conductive nanocomposite paper, in which MWCNTs were partially exposed from the cellulose-[bmIm][Cl] thin films (Fig. 18) [152]. This single contiguous nanocomposite paper can avoid the use of a separate electrolyte and spacer and is versatile to various supercapacitors and LIBs with electrolytes including aqueous solvents, room temperature ionic liquids, and bioelectrolytes (Fig. 18). As a consequence, it was used as electrode for various flexible supercapacitor, battery, hybrid, and dual-storage battery-in-supercapacitor 
Table 6

Literature data on carbon nanomaterials/biomass composites-based electrodes for supercapacitor or battery applications.

\begin{tabular}{|c|c|c|c|c|c|}
\hline Electrodes & Preparation & Conductivity & $\begin{array}{l}\text { Device performance: capacity }\left(\mathrm{Fg}^{-1}\right) \text { or } \\
\text { capacitance }\left(\mathrm{mA} \mathrm{h}^{-1}\right) \text { or energy density } \\
\left(\mathrm{Wh} \mathrm{kg}^{-1}\right) \text { or power density }\left(\mathrm{kW} \mathrm{kg}^{-1}\right)\end{array}$ & Remarks & Ref. \\
\hline $\begin{array}{l}\text { Cellulose } \\
\text { fibers/[bmIm][Cl]/vertically } \\
\text { grown CNTs conductive } \\
\text { nanocomposite paper }\end{array}$ & $\begin{array}{l}\text { Infiltrating } \\
\text { cellulose } /([\mathrm{bmIm}][\mathrm{Cl}]) \text { solution } \\
\text { into the MWNT film }\end{array}$ & 1 & $\begin{array}{l}36 \mathrm{Fg}^{-1} \text { (in KOH electrolyte) } \\
22 \mathrm{~F} \mathrm{~g}^{-1} \text { (in RTIL electrolyte) } \\
13 \mathrm{Wh} \mathrm{kg}^{-1} \\
1.5 \mathrm{~kW} \mathrm{~kg}^{-1} \\
110 \mathrm{~mA} \mathrm{~h}^{-1} \text { at } 10 \mathrm{mAg}^{-1}\end{array}$ & $\begin{array}{l}\text { The nanocomposite paper contains MWNTs as the } \\
\text { working electrode and the cellulose surrounding } \\
\text { individual MWNTs, as well as the extra layer as the } \\
\text { spacer and the RTIL in cellulose as the } \\
\text { self-sustaining electrolyte }\end{array}$ & [152] \\
\hline $\begin{array}{l}\text { CNFs/MWCNT nanohybrid } \\
\text { aerogel }\end{array}$ & Supercritical $\mathrm{CO}_{2}$ drying & 1 & $\begin{array}{l}178 \mathrm{Fg}^{-1} \text { at } 5 \mathrm{mV} \mathrm{s}^{-1} \\
13.6 \mathrm{~mW} \mathrm{~cm}^{-2} \\
20 \mathrm{~mW} \mathrm{~h} \mathrm{~cm}^{-2}\end{array}$ & $\begin{array}{l}\text { (1) All-solid-state flexible supercapacitors are } \\
\text { fabricated using CNFs/MWCNTs film as electrode } \\
\text { material and charge collector } \\
\text { (2) The device remains at } 99.9 \% \text { of the initial } \\
\text { capacitance after } 1000 \text { cycles }\end{array}$ & [153] \\
\hline $\begin{array}{l}\text { Microfibrillated } \\
\text { cellulose/MWCNT } \\
\text { composite }\end{array}$ & Buried-in method & $8.2 \times 10^{-4} \mathrm{Scm}^{-1}$ & $154.5 \mathrm{mF} \mathrm{cm}^{-2}$ at $20 \mathrm{mV} \mathrm{s}^{-1}$ & $\begin{array}{l}\text { Flexible all solid-state supercapacitors were } \\
\text { fabricated for tests }\end{array}$ & [154] \\
\hline $\begin{array}{l}\text { SWCNTs or AgNWs/paper } \\
\text { composite }\end{array}$ & The Meyer rod coating method & $10 \Omega \mathrm{sq}^{-1}$ & $\begin{array}{l}200 \mathrm{Fg}^{-1} \\
30-47 \mathrm{Wh} \mathrm{kg}^{-1} \\
200,000 \mathrm{~W} \mathrm{~kg}^{-1}\end{array}$ & $\begin{array}{l}\text { (1) Capacitor owns a stable cycling life over } 40,000 \\
\text { cycles } \\
\text { (2) Conductive paper can also been used as an } \\
\text { excellent lightweight current collector in LIBs }\end{array}$ & [155] \\
\hline $\begin{array}{l}\text { CNFs/CNTs/silicon- } \\
\text { conductive } \\
\text { nanopaper }\end{array}$ & $\begin{array}{l}\text { Paper-making technique, } \\
\text { manual Meyer rod coating, } \\
\text { plasma-enhanced chemical } \\
\text { vapor deposition method }\end{array}$ & $\sim 80 \Omega \mathrm{sq}^{-1}$ & $1200 \mathrm{~mA} \mathrm{~h} \mathrm{~g}^{-1}$ at $0.8 \mathrm{Ag}^{-1}$ & $\begin{array}{l}\text { (1) The lightweight and flexible Si-conductive } \\
\text { nanopaper structure performs as LIB anodes } \\
\text { (2) After } 100 \text { cycles, the discharge capacity still } \\
\text { remains } 77 \% \text { compared to the first cycle }\end{array}$ & [157] \\
\hline $\begin{array}{l}\text { Homemade cellulose } \\
\text { paper/CNTs } / \mathrm{MnO}_{2} / \mathrm{CNTs}\end{array}$ & $\begin{array}{l}\text { Solution-based coating of CNTs, } \\
\text { electrodeposition of } \mathrm{MnO}_{2}\end{array}$ & $10.7 \Omega$ & $\begin{array}{l}327 \mathrm{Fg}^{-1} \text { at } 10 \mathrm{mV} \mathrm{s}^{-1} \\
201 \mathrm{Fg}^{-1} \text { at } 200 \mathrm{mV} \mathrm{s}^{-1}\end{array}$ & $\begin{array}{l}\text { The capacitance retention was reached with } 96,93 \text {, } \\
88 \text {, and } 85 \% \text { at the } 20,000 \text { th, } 30,000 \text { th, } 40,000 \text { th, } \\
\text { and } 50,000 \text { th cycles, respectively }\end{array}$ & [151] \\
\hline $\begin{array}{l}\text { Natural wood fiber/CNTs/Sn } \\
\text { film }\end{array}$ & $\begin{array}{l}\text { Solution-based coating of } \\
\text { CNTs, electrodeposition of Sn }\end{array}$ & $\sim 30 \Omega \mathrm{sq}^{-1}$ & $339 \mathrm{mAhg}^{-1}$ at $84 \mathrm{mAg}^{-1}$ & $\begin{array}{l}\text { Natural wood fiber/CNTs/Sn film composite } \\
\text { electrode-based Na-ion batteries were developed }\end{array}$ & [19] \\
\hline $\begin{array}{l}\text { Graphene-cellulose paper } \\
\text { membrane material }\end{array}$ & $\begin{array}{l}\text { Filtering a GNS suspension } \\
\text { through a filter paper }\end{array}$ & $6 \Omega \mathrm{cm}$ & $120 \mathrm{Fg}^{-1}$ & $\begin{array}{l}\text { The supercapacitor retains }>99 \% \text { capacitance over } \\
5000 \text { cycles }\end{array}$ & [163] \\
\hline $\begin{array}{l}\text { Graphene/cellulose } \\
\text { composite paper }\end{array}$ & Paper-making process & $11.6 \mathrm{~S} \mathrm{~m}^{-1}$ & $\begin{array}{l}252 \mathrm{Fg}^{-1} \text { at } 1 \mathrm{Ag}^{-1} \\
257 \mathrm{mAh}^{-1} \text { at } 200 \mathrm{mAg}^{-1}\end{array}$ & $\begin{array}{l}\text { The flexible and mechanically tough composite } \\
\text { works well in both supercapacitors and LIBs }\end{array}$ & [164] \\
\hline $\begin{array}{l}\text { Graphene sheets/cotton cloth } \\
\text { nanocomposite }\end{array}$ & Brush-coating and drying & $225 \Omega \mathrm{cm}^{-1}$ & $\begin{array}{l}326.8 \mathrm{Fg}^{-1} \text { at } 10 \mathrm{mV} \mathrm{s}^{-1}, 7.13 \mathrm{Wh} \mathrm{kg}^{-1} \text { in } 6 \mathrm{M} \\
\mathrm{KOH} \text { electrolyte } \\
73.2 \mathrm{Fg}^{-1} \text { at } 0.1 \mathrm{Ag}^{-1}, 12.3 \mathrm{Wh} \mathrm{kg}^{-1} \text { in } 2 \mathrm{M} \\
\mathrm{EMIMBF}_{4} / \text { acetonitrile electrolyte }\end{array}$ & $\begin{array}{l}\text { The supercapacitors fabricated using the GNSs-CC } \\
\text { composite have good cycle durability in both } 6 \mathrm{M} \\
\text { KOH and } 2 \mathrm{M} \text { EMIMBF } 4 \text { /acetonitrile electrolytes } \\
\text { (6-7\% decay of capacitance after } 1500 \text { cycles) }\end{array}$ & [165] \\
\hline CNFs-RGO hybrid aerogels & Supercritical $\mathrm{CO}_{2}$ drying & $100 \mathrm{Sm}^{-1}$ & $\begin{array}{l}207 \mathrm{~F} \mathrm{~g}^{-1} \text { at } 5 \mathrm{mV} \mathrm{s}^{-1} \\
15.5 \mathrm{~mW} \mathrm{~cm}^{-2} \\
20 \mathrm{~mW} \mathrm{~h} \mathrm{~cm}^{-2}\end{array}$ & $\begin{array}{l}\text { The device capacitance still retains about } 99.1 \% \text { of } \\
\text { the initial capacity after } 5000 \text { charge-discharge } \\
\text { cycles }\end{array}$ & [166] \\
\hline CNFs- $[\mathrm{RGO}]_{n}$ hybrid paper & LbL self-assembly approach & $\begin{array}{l}2.4 \mathrm{k} \Omega \mathrm{m}^{-1}(20 \\
\text { layers of } \mathrm{RGO})\end{array}$ & $1.73 \mathrm{mF} \mathrm{cm}^{-2}$ at $5 \mathrm{mV} \mathrm{s}^{-1}$ & $\begin{array}{l}\text { After } 5000 \text { cycles, the capacitance decay is } \sim 19 \% \\
\text { The transmittances of T-SC- } 10 \text { and T-SC- } 20 \text { are } \\
\text { about } 56 \% \text { and about } 30 \% \text { (at } 550 \mathrm{~nm} \text { ) respectively }\end{array}$ & [167] \\
\hline $\begin{array}{l}\text { Carbon } \\
\text { nanomaterials-cellulose } \\
\text { paper composite }\end{array}$ & $\begin{array}{l}\text { Drawing with a graphite rod on } \\
\text { standard printing paper }\end{array}$ & $223 \Omega \mathrm{cm}^{-1}$ & $\begin{array}{l}2.3 \mathrm{mF} \mathrm{cm}^{-2} \text { at } 200 \mathrm{mAg}^{-1} \\
12 \mathrm{Fg}^{-1}\end{array}$ & $\begin{array}{l}\text { (1) Paper supercapacitors by a solvent-free } \\
\text { drawing method were developed } \\
\text { (2) The supercapacitor has excellent cycling } \\
\text { performance with nearly } 100 \% \text { retention of } \\
\text { capacity up to } 3000 \text { cycles }\end{array}$ & [159] \\
\hline
\end{tabular}




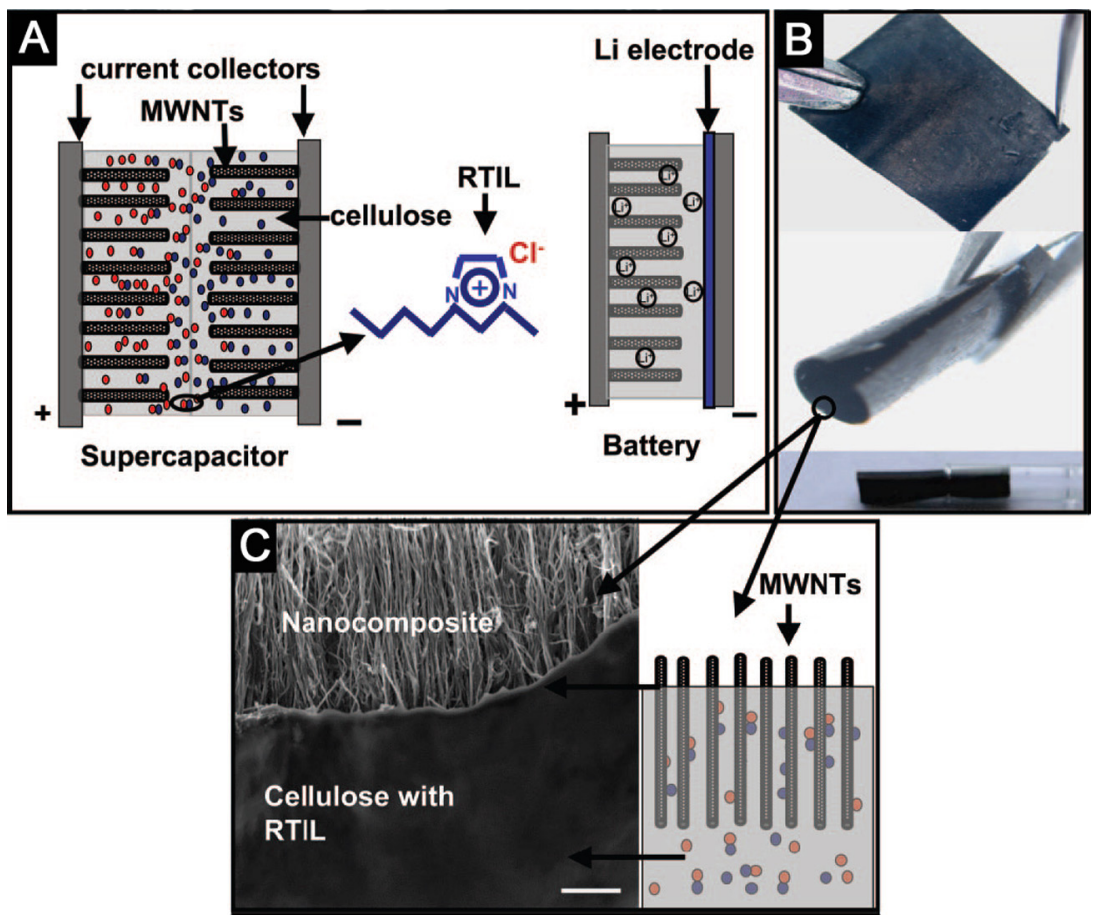

Fig. 18. Fabrication and application of the cellulose fibers/[bmIm] [Cl]/vertically grown CNTs conductive nanocomposite paper units. (A) Schematic of the supercapacitor and LIB assembled by using nanocomposite paper units. (B) Photographs of the nanocomposite units demonstrating flexible property. (C) SEM image and corresponding schematic of the nanocomposite paper showing MWNTs protruding from the cellulose-[bmIm][Cl] thin films [152]. Copyright 2007. Reproduced with permission from the National Academy of Sciences.

devices, and the assembled devices displayed excellent electrochemical performance (Table 6). Recently, CNFs/MWCNT composites have also been successfully used as electrode for constructing high-performance all-solidstate flexible supercapacitors (Table 6) $[153,154]$.

It is worth noting that, in the most recent years, Cui, $\mathrm{Hu}$ and their colleagues have paid much attention on the development of nanostructured, highly conductive cellulose paper for flexible energy and electronic devices $[14,19,151,155-160]$. They demonstrated the generation of conductive electrodes on commercially available paper via forming conformal coating of single-walled carbon nanotubes (SWCNTs) or silver nanowire (AgNWs) films on the paper. The intrinsic properties of paper including high solvent absorption and strong binding with nanomaterials allow easy and scalable coating procedures by using simple solution processes (Fig. 19A and B). The prepared conductive paper has a sheet resistance as low as $1 \Omega \mathrm{sq}^{-1}$. Supercapacitors based on the CNT-conductive paper show excellent performance (on the basis of CNT mass): a specific capacitance of $200 \mathrm{Fg}^{-1}$ (Fig. 19C), a specific energy of $30-47 \mathrm{Wh} \mathrm{kg}^{-1}$, a specific power of $200 \mathrm{~kW} \mathrm{~kg}^{-1}$, and a stable cycling life over 40,000 cycles. This conductive paper has also been used as an excellent lightweight current collector in LIBs to replace the existing metallic counterparts (Fig. 19D). These results indicate that the performance of the prepared conductive paper is competitive with conventional metal foils and its related electrodes in which similar chemistries are used [155].

Cui, $\mathrm{Hu}$ and their colleagues carried out the first study on the optical properties of nanopaper substrates, and developed transparent and conductive composite materials including tin-doped indium oxide, CNTs and AgNWs have been achieved on nanopaper substrates, opening up wide applications in flexible optoelectronics and electrochemical devices [156]. They also reported a CNFs/CNTs/silicon-conductive nanopaper for LIBs, the thin-layer of silicon was deposited on the CNFs/CNTs substrate through a plasma-enhanced chemical vapor deposition method. Such lightweight and flexible Siconductive nanopaper structure presents a stable capacity of $1200 \mathrm{mAhg}^{-1}$ for 100 cycles in half Li-ion cells [157].

Though its energy density is somewhat lower than that of LIB, sodium (Na)-ion battery offers a fascinating alternative for low cost energy storage, because of the huge availability of sodium, its low price and the similarity of both Li and Na insertion chemistries [161]. Recently, Hu et al. demonstrated that the soft and mesoporous wood fiber substrate can be utilized as an attractive platform for low cost Na-ion battery electrode. A Sn thin film was deposited on a CNTs-precoating hierarchical wood fiber substrate, and the composite electrode thereby obtained was used as the anode for Na-ion battery, which can reach a stable cycling performance of 400 cycles with an initial capacity of $339 \mathrm{mAhg}^{-1}$ at a current density of $84 \mathrm{mAg}^{-1}$ (Fig. 20A). These exciting properties that come from the natural wood fiber-based $\mathrm{Sn}$ anode can simultaneously address the critical challenges associated with conventional Sn anodes. On the one hand, the soft nature of wood fibers can effectively accommodate the large volume expansion associated with the sodiation 

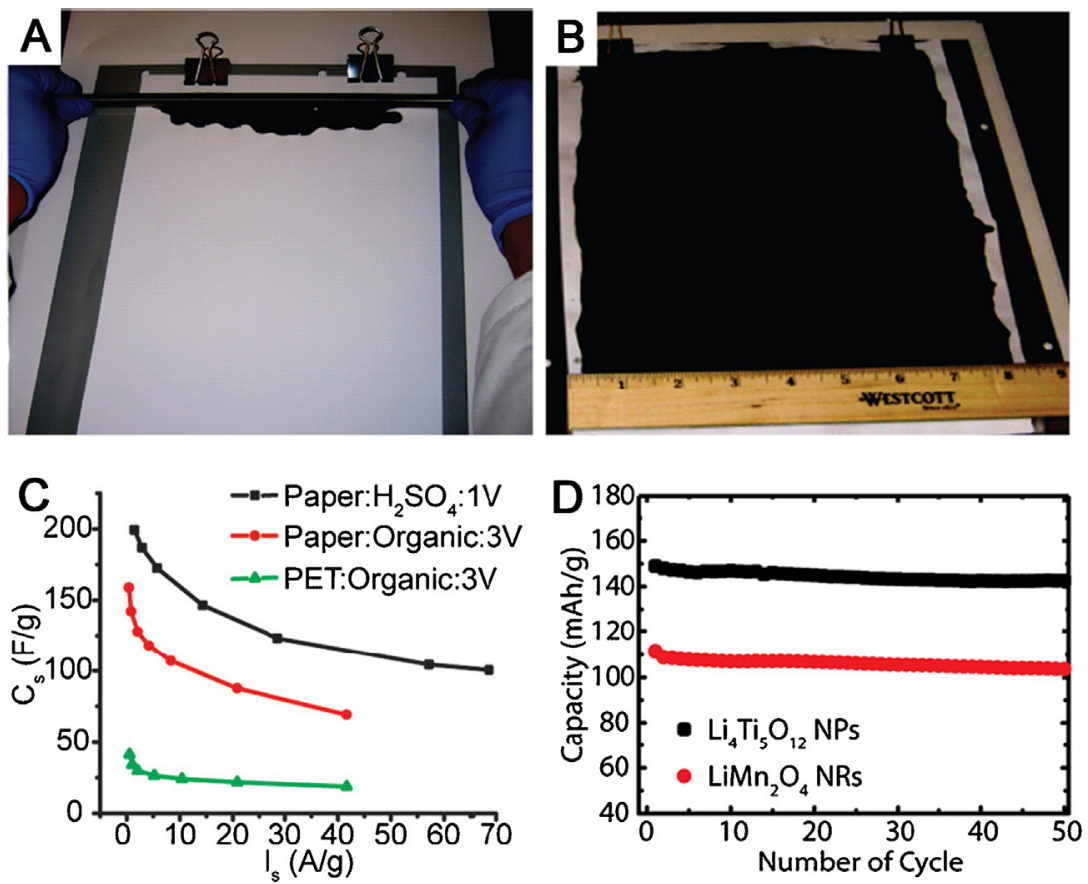

Fig. 19. (A) Conformal coating of CNT or Ag NW ink on commercial Xerox paper via Meyer rod method. (B) The photograph of conductive Xerox paper after CNT coating. (C) Gravimetric capacitances of CNTs-conductive paper at various currents measured in aqueous and organic electrolytes, and data from

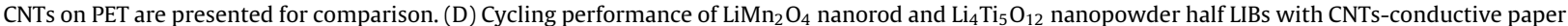
as the current collectors [155].

Copyright 2009. Reproduced with permission from the National Academy of Sciences.

process (Fig. 20B). On the other hand, the hierarchical and mesoporous structure functions as an electrolyte reservoir that can enhance the ion transport kinetics (Fig. 20C) [19].

\subsubsection{Graphenes/biomass composites}

The combination of CNTs with cellulose paper has shown promising application as electrodes of flexible energy storage devices. However, the selection and functionalization of diverse carbon nanomaterials remains optimization to further improve the performance of carbon-cellulose composites. Graphene, a two-dimensional material consisting of a single layer of carbon atoms arranged in a honeycomb or chicken wire structure [162], has been extensively demonstrated as another outstanding candidate. Cheng and colleagues developed a graphene-cellulose paper membrane material as a flexible electrode via a simple filtering method (Fig. 21A). Via the strong electrostatic interaction, graphenes cover the cellulose fibers tightly (Fig. 21B), and are distributed through the macroporous texture of the filter paper to form a conductive interwoven network. Due to the large capacitance $\left(120 \mathrm{Fg}^{-1}\right)$, low electrical resistance, and high strength, when the graphene-cellulose paper electrode was used as freestanding and binder-free electrodes for flexible supercapacitors, satisfied performance was achieved (Fig. 21C and D) [163]. Various graphene/cellulose composites, such as graphene/cellulose pulp composite, graphene sheets/cotton cloth composite, CNFs-reduced graphene oxide (RGO) hybrid aerogels, and CNFs-[RGO $]_{n}$ hybrid paper, have been recently fabricated via diverse process, and all these composites showed excellent performances as the electrode materials of supercapacitors (Table 6) [164-167].

Most of the previously reported electronically conductive polymers or flexible carbon nanomaterials-cellulose paper composite electrodes were fabricated by solutionbased processes, which involve dispersing the active materials in a special solvent, followed by reforming the electrode on a substrate. The use of environmentally unfriendly chemicals and the requirements of posttreatment pose challenges for the wide applications of the techniques. More recently, Cui et al. developed a solvent-free approach to fabricate supercapacitor electrodes, i.e. by drawing with a graphite rod on standard printing paper. The supercapacitors thus fabricated show stable long cycling performance with $90 \%$ capacity retention after 15,000 cycles and a high areal capacitance of $2.3 \mathrm{mF} \mathrm{cm}^{-2}$. The drawing approach holds promising extension to fabricate other types of low cost energy storage device electrodes [159].

The above-mentioned composite electrodes typically derive high electronic conductivity from conducting materials (e.g. CNTs, graphene, conducting polymers), and fast ion transport from the hierarchical porosity of cellulose. $\mathrm{Hu}$ and colleagues clearly verified that mesopores within a cellulose fiber act as an electrolyte reservoir and provide extra paths for ion transport. The use of porous, electrochemically inert cellulose paper as a substrate may sacrifice some volume energy and power density; however it provides efficient utilization of active storage materials at high rates [160]. 
A
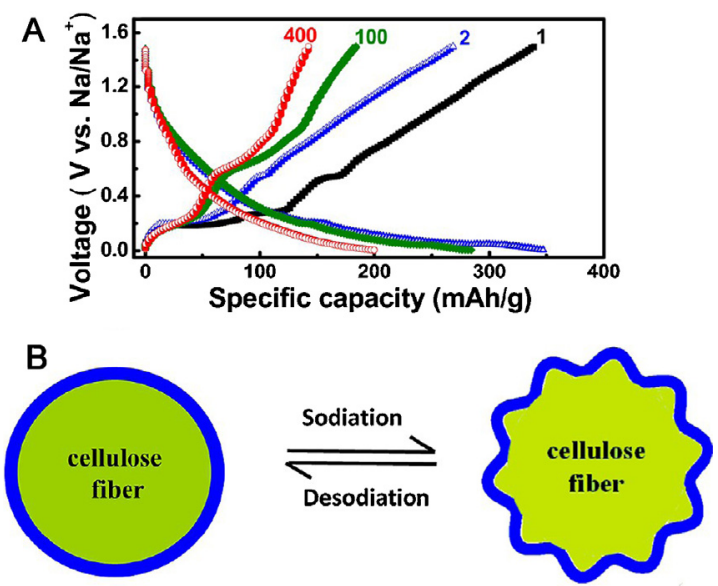

C

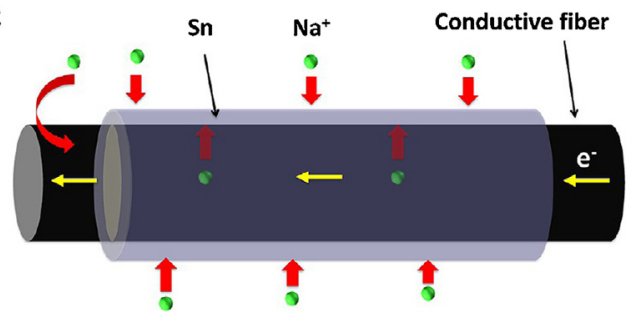

Fig. 20. (A) Discharge-charge profiles of the Na-ion battery based on the anode of $50 \mathrm{~nm}$ Sn on CNTs-precoating wood fiber (Sn@WF) at a rate of C/10. (B) Schematic of how the soft wood fibers release the sodiation generated stresses experienced by the Sn@WF electrode. (C) Schematic of the dual pathways for $\mathrm{Na}^{+}$transport that effectively enhance the kinetics of the Sn@WF anodes for Na-ion batteries [19].

Copyright 2013. Reproduced with permission from the American Chemical Society.

\subsection{Biomass-derived small molecules as electrode materials}

Organic compounds offer new possibilities for high energy/power density, cost-effective, environmentally friendly, and functional rechargeable lithium batteries. For a long time, they have not constituted an important class of electrode materials, partly because of the large success and rapid development of inorganic intercalation compounds. It is now becoming mandatory to develop renewable organic electrodes through eco-efficient processes and to decrease the consumption of non-renewable inorganic resources, the amount of waste produced as well as energy consumption [1]. In recent years, however, exciting progress has been made, bringing organic electrodes to the attention of the energy storage community [168]. Especially, the biomass-derived organic materials have the potential to boost the capacity. Recently, the feasibility of using several active organic molecules that can be simply prepared from natural products common in living systems as electrode materials has been successfully developed by Tarascon and colleagues.

Tarascon et al. firstly investigated the oxocarbon salt, $\mathrm{Li}_{2} \mathrm{C}_{6} \mathrm{O}_{6}$, as a candidate for lithium-inserting positive electrodes. It can electrochemically react with $\mathrm{Li}^{+}$by using carbonyl groups as redox centres, and can be synthesized from the natural organic sources through low-cost processes without using toxic solvents (Fig. 22). As compared with the few recent reports on carbonyl based organics, $\mathrm{Li}_{2} \mathrm{C}_{6} \mathrm{O}_{6}$, turned out to reversibly intercalate four extra lithium per unit formula at an average voltage of $2.5 \mathrm{~V}$, leading to energy densities and power-rate performances that compare to conventional cathodes with the advantage of being fully sustainable

Table 7

Small molecules derived from biomass as electrode materials for LIBs.

\begin{tabular}{|c|c|c|c|c|c|}
\hline Compound & Structure & $E(\mathrm{~V}) \mathrm{Vs} \mathrm{Li}^{+} / \mathrm{Li}^{0}$ & Capacity ( $\left.\mathrm{mA} \mathrm{h} \mathrm{g}^{-1}\right)$ & Remarks & Ref. \\
\hline $\begin{array}{l}\text { Dilithium rhodizonate salt } \\
\left(\mathrm{Li}_{2} \mathrm{C}_{6} \mathrm{O}_{6}\right)\end{array}$ & 0 & 2.5 & 580 & $\begin{array}{l}\text { Contains carbonyl groups } \\
\text { capable of reversibly reacting } \\
\text { with four extra } \mathrm{Li}^{+} \text {per formula }\end{array}$ & [169] \\
\hline $\begin{array}{l}\text { Tetralithium rhodizonate salt } \\
\left(\mathrm{Li}_{4} \mathrm{C}_{6} \mathrm{O}_{6}\right)\end{array}$ & 0 & 1.8 & $\sim 200$ & $\begin{array}{l}\text { Contains carbonyl groups } \\
\text { capable of reversibly reacting } \\
\text { with two extra } \mathrm{Li}^{+} \text {per formula }\end{array}$ & {$[170]$} \\
\hline Di-lithium trans-trans-muconate & & 1.4 & 150 & $\begin{array}{l}\text { With carboxylate groups } \\
\text { capable of reversibly reacting } \\
\text { with one extra } \mathrm{Li}^{+} \text {per formula }\end{array}$ & {$[171]$} \\
\hline Di-lithium terephthalate & & 0.8 & 300 & $\begin{array}{l}\text { With carboxylate groups } \\
\text { capable of reversibly reacting } \\
\text { with two extra } \mathrm{Li}^{+} \text {per formula }\end{array}$ & {$[171]$} \\
\hline $\begin{array}{l}\text { Lithium 2,6-bis } \\
\text { (ethoxycarbonyl)-3,7-dioxo-3,7- } \\
\text { dihydro-s-indacene-1,5-bis(olate) }\end{array}$ & & $\sim 1.96 \sim 1.67$ & 125 & $\begin{array}{l}\text { With both carbonyls and ester } \\
\text { redox centers capable of } \\
\text { reversibly reacting with two } \\
\text { extra } \mathrm{Li}^{+} \text {per formula }\end{array}$ & {$[172]$} \\
\hline
\end{tabular}


A
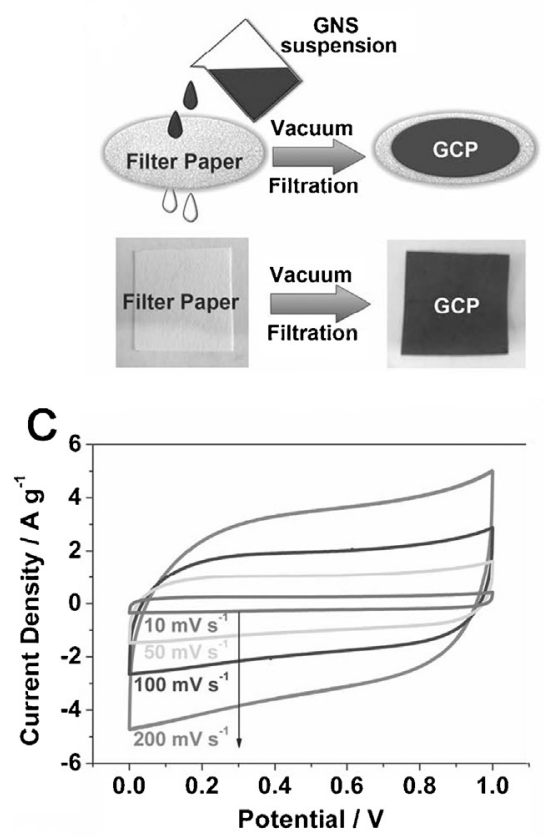
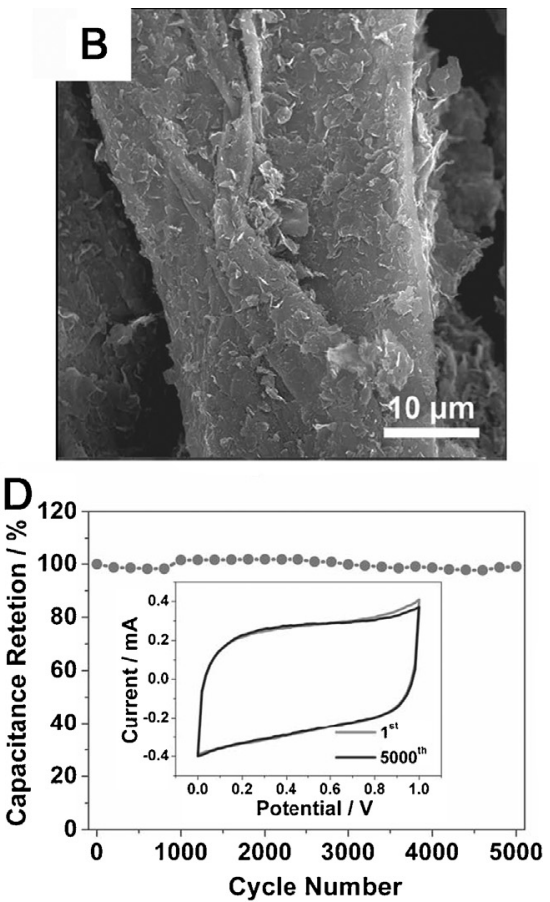

Fig. 21. (A) Schematic of the fabrication process of the graphene-cellulose paper membrane material.(B)Typical SEM image of the graphene-cellulose paper electrode, indicating the anchor of graphenes on the cellulose fiber surface. (C) Cyclic voltammetry (CV) curves of the graphene-cellulose paper electrode in $1 \mathrm{M} \mathrm{H}_{2} \mathrm{SO}_{4}$, showing an excellent capacitive behavior. (D) Cyclic performance of the graphene-cellulose paper electrode measured at $50 \mathrm{mV} \mathrm{s}{ }^{-1}$. Inset: CV curves of the 1 st and the 5000th cycle [163].

Copyright 2011. Reproduced with permission from WILEY-VCH Verlag GmbH \& Co., KGaA.

as it is made from the oxidation of the sugar inositol [169]. Consequently, $\mathrm{Li}_{4} \mathrm{C}_{6} \mathrm{O}_{6}$ [170], $\mathrm{Li}_{2} \mathrm{C}_{8} \mathrm{H}_{4} \mathrm{O}_{4}$ ( $\mathrm{Li}$ terephthalate) [171], $\mathrm{Li}_{2} \mathrm{C}_{6} \mathrm{H}_{4} \mathrm{O}_{4}$ (Li trans-trans-muconate) [171] and lithium 2,6-bis(ethoxycarbonyl)-3,7-dioxo-3,7dihydro-s-indacene-1,5-bis(olate) [172] compounds were reported as key electrode materials for LIBs with attractive performances (Table 7). These molecules can also be readily prepared from biomass via eco-efficient processes. However, to realize green, sustainable, fully-organic LIBs with comparable energy densities and powerrate performances and to completely understand the structure-function relationship of these small molecule compounds, further investigations currently remains necessary.

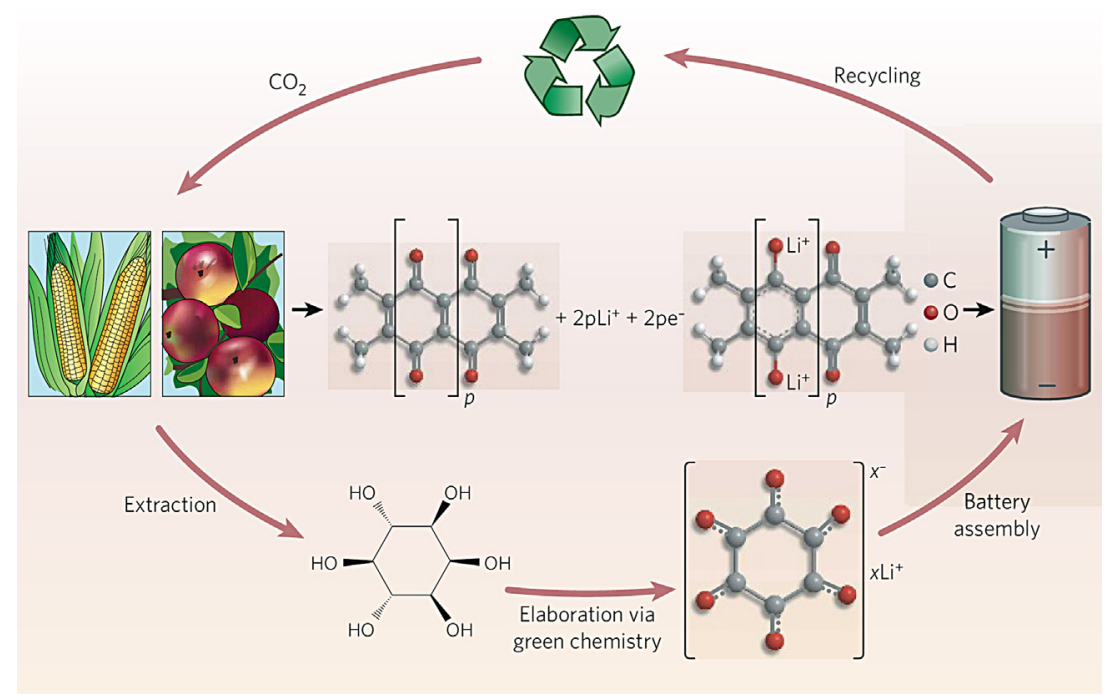

Fig. 22. The proposed sustainable organic-based LIBs on the basis of biomass-derived electrode materials. Electrochemically active Li ${ }_{2} \mathrm{C}_{6} \mathrm{O}_{6}$ can be prepared from corn-extracted myo-inositol, whereas electrochemically active polyquinone can be polymerized from apples-extracted malic acid (center) [1]. Copyright 2008. Reproduced with permission from the Nature Publishing Group. 


\section{Conclusion and perspectives}

Recent investigations have resulted in a significantly improved comprehension of the critical challenges for electrochemical energy storage systems. Biomass-derived materials have been demonstrated as very promising alternatives to conventional polyolefin separators, binders and substantial electrode materials in electrochemical energy storage devices and the recent processes have been emphasized in this review. Owing to their sustainable, environmental friendly, cost-effective characteristics, the application of biomass-derived materials opens up new possibilities for the production of green, low-cost, upscalable and lightweight energy storage systems, even fully recyclable paper-based batteries on a large industrial scale.

Although the implementation of biomass-derived materials in green and sustainable electrochemical energy storage systems holds great promise in a number of applications ranging from separators, binders to electrode materials, it is clear that considerable critical challenges still remain to be solved:

(1) The principal challenge in the use of biomass-derived separators is the control of thickness and porosity (particularly pore size and distribution, and thermal shutdown property). In addition, the hygroscopic nature, low mechanical strength and flammable property, are also the challenges need to be overcome for the development of biomass-derived separators for energy storage.

(2) For the biomass-derived binders, some critical drawbacks have to be overcome such as variable quality, weaker adhesion on foils, stiffness at low temperature and high moisture uptake. Strict quality standards need to be issued to control the production quality and utilization, and the combination of biomass-derived binders with some other flexible binders can improve the dispersion and adhesion on foils and ameliorate the flexibility at low temperature.

(3) The energy densities of biomass-derived energy devices are normally quite lower than those of conventional metal-based systems. The critical issue in the use of biomass-derived materials as electrode materials is the fact that they by themselves are electronically insulating and usually limited in functionalities, and thus the proper integration with other conductive and functional materials is prerequisite and faces many challenges. In addition, the stability, conformability and self-discharge of biomass-derived energy devices deserve intensive fundamental research.

Future research can emphasize the following key areas of development, which might favor the realization of more intriguing electrochemical energy storage devices on the basis of biomass-derived materials:

(1) Until now, most attention was paid to very numbered biomass materials, especially cellulose and its derivates. However, numerous other biomass materials (e.g. lignin, marine polysaccharides, and biomass from agro-forestry wastes), with their own specific structures and properties, also possess the potential applications as key materials for energy application, and thus merit intensive research devotion in the future. Additionally, large-scale production of biomassderived materials with finely tuned structures and properties in even more low-cost and environmental friendly manners is critical for their applications in the energy storages.

(2) It is obligatory to further improve their individual performance of biomass-derived key materials for energy devices, even to endow them with additional functions by physical or chemical manipulation to biomass. For instance, by incorporating the biomass-derived separator with proper electro-active polymers, it is expected that the fabricated switchable separator can transform from an isolating state to a conducting state at a defined charging voltage to bypass the overcharging current and further improve the safety of the batteries.

(3) It can be expected that the biomass-derived materials can also play promising roles in the next-generation electrochemical energy devices, such as all-solid-state LIBs, Li-S batteries and Li-air batteries, with more significance and more challenges. The all-paper-device, in which all components are made by cellulosederived materials, is also very promising and deserves intensive research efforts as a flexible, sustainable and high-performance energy device candidate. More importantly, the large-scale and low-cost fabrication of paper-based energy devices potentially can be realized by using 3-D printing and other high-throughput nanofabrication techniques in the future [173].

\section{Acknowledgments}

We thank Dr. Qingshan Kong, Dr. Chuanjian Zhang, Dr. Shanmu Dong, and Mr. Jianjun Zhang for their fruitful discussions. This work was supported by the National High Technology Research and Development Program of China (863 program, No. 2013AA050905), the National Program on Key Basic Research Project of China (No. MOST2011CB935700), the Instrument Developing Project of the Chinese Academy of Sciences (No. YZ201137), the Key Research Program of the Chinese Academy of Sciences (Grant No. KGZD-EW-202-2), National Natural Science Foundation of China (Nos. 21275151, 21271180 and 21344003), and Qingdao Key Lab of Solar Energy Utilization \& Energy Storage Technology.

\section{References}

[1] Armand M, Tarascon JM. Building better batteries. Nature 2008;451:652-7.

[2] Yang Z, Zhang J, Kintner-Meyer MCW, Lu X, Choi D, Lemmon JP, Liu J. Electrochemical energy storage for green grid. Chem Rev 2011;111:3577-613.

[3] Rolison DR, Nazar LF. Electrochemical energy storage to power the 21st century. MRS Bull 2011;36:486-93.

[4] Goodenough JB, Kim Y. Challenges for rechargeable Li batteries. Chem Mater 2010;22:587-603.

[5] Goodenough JB, Park KS. The Li-ion rechargeable battery: a perspective. J Am Chem Soc 2013;135:1167-76.

[6] Choi NS, Chen Z, Freunberger SA, Ji X, Sun YK, Amine K, Yushin G, Nazar LF, Cho J, Bruce PG. Challenges facing lithium 
batteries and electrical double-layer capacitors. Angew Chem Int Ed 2012;51:9994-10024.

[7] Béguin F, Frackowiak E, editors. Supercapacitors: materials, systems, and applications. Weinheim: Wiley-VCH; 2013. p. 568.

[8] Guo YG, Hu JS, Wan LJ. Nanostructured materials for electrochemical energy conversion and storage devices. Adv Mater 2008;20:2878-87.

[9] Zhang Q, Uchaker E, Candelaria SL, Cao G. Nanomaterials for energy conversion and storage. Chem Soc Rev 2013;42:3127-71.

[10] Liu J, Zhang JG, Yang Z, Lemmon JP, Imhoff C, Graff GL, Li L, Hu J, Wang C, Xiao J, Xia G, Viswanathan VV, Baskaran S, Sprenkle V, Li $X$, Shao Y, Schwenzer B. Materials science and materials chemistry for large scale electrochemical energy storage: from transportation to electrical grid. Adv Funct Mater 2013;23:929-46

[11] Heinimö J, Junginger M. Production and trading of biomass for energy - an overview of the global status. Biomass Bioenergy 2009;33:1310-20.

[12] Naik SN, Goud VV, Rout PK, Dalai AK. Production of first and second generation biofuels: a comprehensive review. Renew Sust Energy Rev 2010;14:578-97.

[13] Nyholm L, Nyström G, Mihranya A, Strømme M. Toward flexible polymer and paper-based energy storage devices. Adv Mater 2011;23:3751-69.

[14] Zheng G, Cui Y, Karabulut E, Wågberg L, Zhu H, Hu L. Nanostructured paper for flexible energy and electronic devices. MRS Bull 2013;38:320-5.

[15] Jabbour L, Bongiovanni R, Chaussy D, Gerbaldi C, Beneventi D. Cellulose-based Li-ion batteries: a review. Cellulose 2013:20:1523-45.

[16] Osburn L, Osburn J. Biomass resources for energy and industry; 1993. http://www.ratical.org/renewables/biomass.html [accessed April 2013].

[17] Laurichesse S, Avérous L. Chemical modification of lignins: towards biobased polymers. Prog Polym Sci 2014;39:1266-90.

[18] Klemm D, Heublein B, Fink HP, Bohn A. Cellulose: fascinating biopolymer and sustainable raw material. Angew Chem Int Ed 2005;44:3358-93.

[19] Zhu H, Jia Z, Chen Y, Weadock N, Wan J, Vaaland O, Han X, Li T, Hu L. Tin anode for sodium-ion batteries using natural wood fiber as a mechanical buffer and electrolyte reservoir. Nano Lett 2013;13:3093-100

[20] Klemm D, Kramer F, Moritz S, Lindström T, Ankerfors M, Gray D, Dorris A. Nanocelluloses: a new family of nature-based materials. Angew Chem Int Ed 2011;50:5438-66.

[21] Laurienzo P. Marine polysaccharides in pharmaceutical applications: an overview. Mar Drugs 2010;8:2435-65

[22] Yoshio M, Brodd RJ, Kozawa A, editors. Lithium-ion batteries: science and technologies. New York: Springer; 2009. p. 452.

[23] Daniel C, Besenhard JO, editors. Handbook of battery materials. 2nd ed. Weinheim: Wiley-VCH; 2011. p. 1023.

[24] Arora P, Zhang Z. Battery separators. Chem Rev 2004;104:4419-62.

[25] Aricò AS, Bruce P, Scrosati B, Tarascon JM, van Schalkwijk W. Nanostructured materials for advanced energy conversion and storage devices. Nat Mater 2005;4:366-77.

[26] Ko JM, Min BG, Kim DW, Ryu KS, Kim KM, Lee YG, Chang SH. Thinfilm type Li-ion battery, using a polyethylene separator grafted with glycidyl methacrylate. Electrochim Acta 2004;50:367-70.

[27] Jeong YB, Kim DW. Effect of thickness of coating layer on polymercoated separator on cycling performance of lithium-ion polymer cells. J Power Sources 2004;128:256-62.

[28] Gao K, Hu X, Yi T, Dai C. PE-g-MMA polymer electrolyte membrane for lithium polymer battery. Electrochim Acta 2006;52: 443-9.

[29] Kim JY, Lee Y, Lim DY. Plasma-modified polyethylene membrane as a separator for lithium-ion polymer battery. Electrochim Acta 2009;54:3714-9.

[30] Venugopal G, Moore J, Howard J, Pendalwar S. Characterization of microporous separators for lithium-ion batteries. J Power Sources 1999;77:34-41.

[31] Costa CM, Silva MM, Lanceros-Méndez S. Battery separators based on vinylidene fluoride (VDF) polymers and copolymers for lithium ion battery applications. RSC Adv 2013:3:11404-17.

[32] Etacheri V, Marom R, Elazari R, Salitra G, Aurbach D. Challenges in the development of advanced Li-ion batteries: a review. Energy Environ Sci 2011:4:3243-62.

[33] Goodenough JB, Kim Y. Challenges for rechargeable batteries. J Power Sources 2011;196:6688-94.

[34] Hietbrink EH, McBreen J, Selis SM, Tricklebank SB, Witherspoon RR. Electrochemical power sources for vehicle propulsion. In: Bockris
JOM, editor. Electrochemistry of cleaner environments. New York: Springer; 1972. p. 47-97.

[35] Danko T. Properties of cellulose separators for alkaline secondary batteries. In: Proceedings of the 10th annual battery conference on applications and advances. Piscataway, NJ: IEEE; 1995. p. 261-4.

[36] Lewis H, Grun C, Salkind A. Cellulosic separator applications: new and improved separators for alkaline rechargeable cells. J Power Sources 1997;65:29-38.

[37] Wang X, Hu J, Long J. Preparation ultra-fine fibrillated lyocell fiber and its application in battery separator. Int J Electrochem Sci 2011;6:4999-5004

[38] Harada T, Nagi H, Kawai H, Nishiyama M. Alkaline battery separator comprising alkali-resistance synthetic fiber, fibrillated organic solvent-spun cellulose fiber and mercerized pulp, and alkaline primary battery. US 8097366 B2: Kuraray Co., Ltd.; 2012.

[39] Kubo Y, Nakajima O, Ogawa K. Separator for alkaline battery and alkaline battery. WO 2013114949 A1: Nippon Kodoshi Corporation; 2013.

[40] Kötz R, Carlen M. Principles and applications of electrochemical capacitors. Electrochim Acta 2000;45:2483-98.

[41] Gozdz A, Plitz I, Du Pasquier A, Shelburne J. Use of electrode-bonded paper separators in non-aqueous electric double-layer capacitors and Li-ion batteries. In: Proceedings of the 201st meeting of the ECS. 2002. Abs\#219.

[42] Gozdz AS. Electrochemical cell comprising lamination of electrode and paper separator members. WO 2003029524A1: Telcordia Tech Inc.; 2003.

[43] Kuribayashi I. Characterization of composite cellulosic separators for rechargeable lithium-ion batteries. J Power Sources 1996;63:87-91.

[44] Zhang LC, Sun X, Hu Z, Yuan CC, Chen CH. Rice paper as a separator membrane in lithium-ion batteries. J Power Sources 2012;204:149-54.

[45] Assaf AG, Haas RH, Purves CB. A new interpretation of the cellulosewater adsorption isotherm and data concerning the effect of swelling and drying on the colloidal surface of cellulose. J Am Chem Soc 1944;66:66-73.

[46] Schmidt M, Heider U, Kuehner A, Oesten R, Jungnitz M, Ignat'ev N, Sartori P. Lithium fluoroalkylphosphates: a new class of conducting salts for electrolytes for high energy lithium-ion batteries. J Power Sources 2001;97-98:557-60

[47] Jabbour L, Destro M, Chaussy D, Gerbaldi C, Penazzi N, Bodoardo $\mathrm{S}$, Beneventi D. Flexible cellulose $/ \mathrm{LiFePO}$ paper-cathodes: toward eco-friendly all-paper Li-ion batteries. Cellulose 2013;20:571-82.

[48] Chun SJ, Choi ES, Lee EH, Kim JH, Lee SY, Lee SY. Eco-friendly cellulose nanofiber paper-derived separator membranes featuring tunable nanoporous network channels for lithium-ion batteries. J Mater Chem 2012;22:16618-26.

[49] Siró I, Plackett D. Microfibrillated cellulose and new nanocomposite materials: a review. Cellulose 2010;17:459-94.

[50] Nogi M, Iwamoto S, Nakagaito AN, Yano H. Optically transparent nanofiber paper. Adv Mater 2009;21:1595-8.

[51] Yano H, Nakahara S. Bio-composites produced from plant microfiber bundles with a nanometer unit web-like network. J Mater Sci 2004;39:1635-8.

[52] Kim JH, Kim JH, Choi ES, Yu HK, Kim JH, Wu Q, Chun SJ, Lee SY, Lee SY. Colloidal silica nanoparticle-assisted structural control of cellulose nanofiber paper separators for lithium-ion batteries. J Power Sources 2013:242:533-40.

[53] Chun SJ, Doh GH, Jung CS, Lee JH, Lee SY. Porous separator using cellulose nanofibers, and method for preparing same. WO 2012050277A1: Republic of Korea: Forestry Administration Forestry Research Institute; 2012.

[54] Zhang JJ, Liu ZH, Kong QS, Zhang CJ, Pang SP, Yue LP, Wang X], Yao JH, Cui GL. Renewable and superior thermal-resistant cellulose-based composite nonwoven as lithium-ion battery separator. ACS Appl Mater Interfaces 2013:5:128-34

[55] Xu Q, Kong QS, Liu ZH, Wang XJ, Liu RZ, Zhang JJ, Yue LP, Duan YL, Cui GL. Cellulose/polysulfonamide composite membrane as a high performance lithium-ion battery separator. ACS Sustain Chem Eng 2014;2:194-9.

[56] Zhang JJ, Yue LP, Kong QS, Liu ZH, Zhou XH, Zhang CJ, Xu Q, Zhang B, Ding GL, Qin BS, Duan YL, Wang QF, Yao JH, Cui GL, Chen LQ. Sustainable, heat-resistant and flame-retardant cellulose-based composite separator for high-performance lithium ion battery. Sci Rep 2014;4, $3935 / 1-8$

[57] Tomohiro S, Takahiro T, Masatoshi M. Separator for electrochemical element, and the electrochemical element using the same. JP 2011187515 A: Mitsubishi Paper Mills Ltd.; 2011. 
[58] Takahiro T, Tomohiro S. Separator for solid electrolytic capacitor, and solid electrolytic capacitor using the same. JP 2011228320 A: Mitsubishi Paper Mills Ltd., 2011.

[59] Takahiro T. Separator for electrochemical element. JP 2011253709 A: Mitsubishi Paper Mills Ltd.; 2011.

[60] Akai H, Banzashi G, Noishiki Y, Umemoto T. Cellulose fiber assembly and production method for same, fibrillated cellulose fiber and production method for same, and cellulose fiber complex. WO 2012067113 A1: Mitsubishi Chemical Corporation; 2012.

[61] Morin BG, Schaeffer JL. Single-layer lithium ion battery separator. US 20130078525 A1: Dreamweaver International Inc.; 2013.

[62] Lee H, Dellatore SM, Miller WM, Messersmith PB. Musselinspired surface chemistry for multifunctional coatings. Science 2007;318:426-30.

[63] Faure E, Falentin-Daudré C, Jérôme C, Lyskawa J, Fournier D, Woisel P, Detrembleur C. Catechols as versatile platforms in polymer chemistry. Prog Polym Sci 2013;38:236-70.

[64] Lee B, Messersmith PB, Israelachvili JN, Waite JH. Musselinspired adhesives and coatings. Annu Rev Mater Res 2011;41: 99-132.

[65] Ryou MH, Lee YM, ParkJK, Choi JW. Mussel-inspired polydopaminetreated polyethylene separators for high-power Li-ion batteries. Adv Mater 2011;23:3066-70.

[66] Ryou MH, Lee DJ, Lee JN, Lee YM, Park JK, Choi JW. Excellent cycle life of lithium-metal anodes in lithium-ion batteries with mussel-inspired polydopamine-coated separators. Adv Energy Mater 2012;2:645-50.

[67] Xu Q, Kong QS, Liu ZH, Zhang JJ, Wang XJ, Liu RZ, Yue LP, Cui GL. Polydopamine-coated cellulose microfibrillated membrane as high performance lithium-ion battery separator. RSC Adv 2014;4:7845-50.

[68] Park M, Zhang XC, Chung MD, Less GB, Sastry AM. A review of conduction phenomena in Li-ion batteries. J Power Sources 2010;195:7904-29.

[69] Rolison DR, Long RW, Lytle JC, Fischer AE, Rhodes CP, McEvoy TM, Bourga ME, Lubers AM. Multifunctional 3D nanoarchitectures for energy storage and conversion. Chem Soc Rev 2009;38:226-52.

[70] Guo JC, Wang CS. A polymer scaffold binder structure for high capacity silicon anode of lithium-ion battery. Chem Commun 2010;46:1428-30.

[71] Liu G, Xun SD, Vukmirovic N, Song XY, Olalde-Velasco P, Zheng HH, Battaglia VS, Wang LW, Yang WL. Polymers with tailored electronic structure for high capacity lithium battery electrodes. Adv Mater 2011;23:4679-83

[72] Wang DY, Ela SE, Zakeeruddin SM, Pechy P, Exnarc I, Wang O Grätzel M. Polymer wiring of insulating electrode materials: an approach to improve energy density of lithium-ion batteries. Electrochem Commun 2009;11:1350-2.

[73] Cai LL, Zhang L, Qu QT, Zheng HH. Progress of electrode binder in lithium ion batteries. Chemistry 2013;76:299-306 (in Chinese).

[74] Yang HQ, Li DP, Han S, Li N, Lin BX. Vanadium-manganese complex oxides as cathode materials for aqueous solution secondary batteries. J Power Sources 1995;58:221-4.

[75] Li CC, Lee JT, Lo CY, Wu MS. Effects of PAA-NH 4 addition on the dispersion property of aqueous $\mathrm{LiCoO}_{2}$ slurries and the cell performance of as-prepared $\mathrm{LiCoO}_{2}$ cathodes. Electrochem Solid State Lett 2005;8:A509-12.

[76] Li CC, Lee JT, Peng XW. Improvements of dispersion homogeneity and cell performance of aqueous-processed $\mathrm{LiCoO}_{2}$ cathodes by using dispersant of PAA $-\mathrm{NH}_{4}$. J Electrochem $\mathrm{Soc}$ 2006;153:A809-15

[77] Yoo M, Frank CW, Mori S. Interaction of poly(vinylidene fluoride) with graphite particles. 1. Surface morphology of a composite film and its relation to processing parameters. Chem Mater 2003;15:850-61.

[78] Choi NS, Lee YG, Park JK. Effect of cathode binder on electrochemical properties of lithium rechargeable polymer batteries. J Power Sources 2002;112:61-6.

[79] Maleki H, Deng GP, Haller IK, Anani A, Howard JN. Thermal stability studies of binder materials in anodes for lithium-ion batteries. J Electrochem Soc 2000;147:4470-5

[80] Holzapfel M, Buqa H, Scheifele W, Novák P, Petrat FM. A new type of nano-sized silicon/carbon composite electrode for reversible lithium insertion. Chem Commun 2005:1566-8.

[81] Yoshio M, Tsumura T, Dimov N. Silicon/graphite composites as an anode material for lithium ion batteries. J Power Sources 2006;163:215-8.

[82] Lee JH, Paik U, Hackley VA, Choi YM. Effect of carboxymethyl cellulose on aqueous processing of natural graphite negative electrodes and their electrochemical performance for lithium batteries. J Electrochem Soc 2005:152:A1763-9.

[83] Lee JH, Paik U, Hackley VA, Choi YM. Effect of poly(acrylic acid) on adhesion strength and electrochemical performance of natural graphite negative electrode for lithium-ion batteries. J Power Sources 2006;161:612-6

[84] Dimov N, Xia YG, Yoshio M. Practical silicon-based composite anodes for lithium-ion batteries: fundamental and technologica features. J Power Sources 2007;171:886-93.

[85] Li J, Lewis RB, Dahn JR. Sodium carboxymethyl cellulose-a potential binder for Si negative electrodes for Li-ion batteries. Electrochem Solid State Lett 2007;10:A17-20

[86] Chou SL, Gao XW, Wang JZ, Wexler D, Wang ZX, Chen LQ Liu HK. Tin/polypyrrole composite anode using sodium carboxymethyl cellulose binder for lithium-ion batteries. Dalton Trans 2011:40:12801-7.

[87] Bridel JS, Azais T, Morcrette M, Tarascon JM, Larcher D. Key parameters governing the reversibility of $\mathrm{Si} /$ carbon/CMC electrodes for Li-ion Batteries. Chem Mater 2010:22:1229-41.

[88] Koo B, Kim H, Cho Y, Lee KT, Choi NS, Cho J. A highly cross-linked polymeric binder for high-performance silicon negative electrodes in lithium ion batteries. Angew Chem Int Ed 2012;51:8762-7.

[89] Lux SF, Schappacher F, Balducci A, Passerini S, Winter M. Low cost Environmentally benign binders for lithium-ion batteries. J Electrochem Soc 2010;157:A320-5

[90] Kim GT, Jeong SS, Joost M, Rocca E, Winter M, Passerini S, Balducci A Use of natural binders and ionic liquid electrolytes for greener and safer lithium-ion batteries. J Power Sources 2011;196:2187-94.

[91] Xu J, Chou SL, Gu OF, Liu HK, Dou SX. The effect of different binders on electrochemical properties of $\mathrm{LiNi}_{1 / 3} \mathrm{Mn}_{1 / 3} \mathrm{Co}_{1 / 3} \mathrm{O}_{2}$ cathode material in lithium ion batteries. J Power Sources 2013;225 $172-8$

[92] Li CC, Wang YW. Importance of binder compositions to the dispersion and electrochemical properties of water-based $\mathrm{LiCoO}_{2}$ cathodes. J Power Sources 2013;227:204-10.

[93] Kovalenko I, Zdyrko B, Magasinski A, Hertzberg B, Milicev Z, Burtovyy R, Luzinov I, Yushin G. A major constituent of brown algae for use in high-capacity Li-ion batteries. Science 2011;334:75-9.

[94] Lee H, Lee BP, Messersmith PB. A reversible wet/dry adhesive inspired by mussels and geckos. Nature 2007;448:338-41.

[95] Lin Q, Gourdon D, Sun CJ, Holten-Andersen N, Anderson TH, Waite JH, Israelachvili JN. Adhesion mechanisms of the mussel foot proteins mfp-1 and mfp-3. Proc Natl Acad Sci USA 2007;104:3782-6.

[96] Lee H, Scherer NF, Messersmith PB. Single-molecule mechanics of mussel adhesion. Proc Natl Acad Sci USA 2006;103:12999-3003.

[97] Matos-Perez CR, White JD, Wilker JJ. Polymer composition and substrate influences on the adhesive bonding of a biomimetic, cross-linking polymer. J Am Chem Soc 2012;134:9498-505.

[98] Ryou MH, Kim J, Lee I, Kim S, Jeong YK, Hong S, Ryu JH, Kim TS Park JK, Lee H, Choi JW. Mussel-inspired adhesive binders for highperformance silicon nanoparticle anodes in lithium-ion batteries. Adv Mater 2013;25:1571-6.

[99] Wang J, Yao Z, Monroe CW, Yang J, Nuli Y. Carbonyl- $\beta$-cyclodextrin as a novel binder for sulfur composite cathodes in rechargeable lithium batteries. Adv Funct Mater 2013;23:1194-201.

[100] Jeong YK, Kwon T, Lee I, Kim TS, Coskun A, Choi JW. Hyperbranched $\beta$-cyclodextrin polymer as an effective multidimensional binder for silicon anodes in lithium rechargeable batteries. Nano Lett 2014;14:864-70

[101] Murase M, Yabuuchi N, Han ZJ, Son JY, Cui YT, Oji H, Komaba S. Crop-derived polysaccharides as binders for high-capacity silicon/graphite-based electrodes in lithium-ion batteries. ChemSusChem 2012;5:2307-11.

[102] Gaberšček M, Bele M, Drofenik J, Dominko R, Pejovnik S. Improved carbon anode for lithium batteries pretreatment of carbon particles in a polyelectrolyte solution. Electrochem Solid State Lett 2000:3:171-3.

[103] Gaberšček M, Bele M, Drofenik J, Dominko R, Pejovnik S. Improved carbon anode properties: pretreatment of particles in polyelectrolyte solution. J Power Sources 2001;97-98:67-9.

[104] Mominko R, Gaberšček M, Drofenik J, Bele M, Pejovnik S, Jamnik J. The role of carbon black distribution in cathodes for Li ion batteries. J Power Sources 2003;119-121:770-3.

[105] Mominko R, Gaberšček M, Drofenik J, Bele M, Jamnik J. Influence of carbon black distribution on performance of oxide cathodes for Li ion batteries. Electrochim Acta 2003;48:3709-16.

[106] Sun J, Huang YQ, Wang WK, Yu ZB, Wang AB, Yuan KG. Application of gelatin as a binder for the sulfur cathode in lithium-sulfur batteries. Electrochim Acta 2008;53:7084-8. 
[107] Huang YQ, Sun J, Wang WK, Wang Y, Yu ZB, Zhang H, Wang AB, Yuan KG. Discharge process of the sulfur cathode with a gelatin binder. J Electrochem Soc 2008;155:A764-7.

[108] Xing W, Xue JS, Dahn JR. Optimizing pyrolysis of sugar carbons for use as anode materials in lithium-ion batteries. J Electrochem Soc 1996; 143:3046-52.

[109] Peled E, Eshkenazi V, Rosenberg Y. Study of lithium insertion in hard carbon made from cotton wool. J Power Sources 1998:76:153-8.

[110] Fey GT, Chen C. High-capacity carbons for lithium-ion batteries prepared from rice husk. J Power Sources 2001:97-98:47-51.

[111] Zhang F, Wang K, Li G, Chen J. Hierarchical porous carbon derived from rice straw for lithium ion batteries with high-rate performance. Electrochem Commun 2009;11:130-3.

[112] Wang L, Schnepp Z, Titirici MM. Rice husk-derived carbon anodes for lithium ion batteries. J Mater Chem A 2013;1:5269-73.

[113] Wang B, Li X, Luo B, Yang J, Wang X, Song Q Chen S, Zhi L. Pyrolyzed bacterial cellulose: a versatile support for lithium ion battery anode baterials. Small 2013;9:2399-404

[114] Zhu H, Wang XL, Yang F, Yang XR. Promising carbons for supercapacitors derived from fungi. Adv Mater 2011;23:2745-8.

[115] Zhu H, Yin J, Wang XL, Wang HY, Yang XR. Microorganism-derived heteroatom-doped carbon materials for oxygen reduction and supercapacitors. Adv Funct Mater 2013;23:1305-12.

[116] Li C, Bai H, Shi G. Conducting polymer nanomaterials: electrosynthesis and applications. Chem Soc Rev 2009;38:2397-409.

[117] Mike JF, Lutkenhaus JL. Recent advances in conjugated polymer energy storage. J Polym Sci B: Polym Phys 2013;51:468-80.

[118] Lu XF, Zhang WJ, Wang C, Wen TC, Wei Y. One-dimensional conducting polymer nanocomposites: synthesis, properties and applications. Prog Polym Sci 2011;36:671-712.

[119] Otero TF, Cantero I. Conducting polymers as positive electrodes in rechargeable lithium-ion batteries. J Power Sources 1999;81-82:838-41.

[120] Veeraraghavan B, Paul J, Haran B, Popov B. Study of polypyrrole graphite composite as anode material for secondary lithium-ion batteries. J Power Sources 2002;109:377-87.

[121] Chen J, Liu Y, Minett AI, Lynam C, Wang J, Wallace GG. Flexible, aligned carbon nanotube/conducting polymer electrodes for a lithium-ion battery. Chem Mater 2007;19:3595-7.

[122] Yang Y, Wang C, Yue B, Gambhir S, Too CO, Wallace GG. Electrochemically synthesized polypyrrole/graphene composite film for lithium batteries. Adv Energy Mater 2012;2:266-72.

[123] Zhao Y, Liu B, Pan L, Yu G. 3D nanostructured conductive polymer hydrogels for high-performance electrochemical devices. Energy Environ Sci 2013:6:2856-70

[124] Kelly FM, Johnston JH, Borrmann T, Richardson MJ. Functionalised hybrid materials of conducting polymers with individual fibres of cellulose. Eur J Inorg Chem 2007;2007:5571-7.

[125] Peng C, Jin J, Chen GZ. A comparative study on electrochemical co-deposition and capacitance of composite films of conducting polymers and carbon nanotubes. Electrochim Acta 2007;53:525-37.

[126] Bjorklund RB, Liedberg B. Electrically conducting composites of colloidal polypyrrole and methylcellulose. Chem Commun 1986:1293-5.

[127] Nyström G, Razaq A, Strømme M, Nyholm L, Mihranyan A. Ultrafast all-polymer paper-based batteries. Nano Lett 2009;9:3635-9.

[128] Strømme M, Frenning G, Razaq A, Gelin K, Nyholm L, Mihranyan A. Ionic motion in polypyrrole-cellulose composites: trap release mechanism during potentiostatic reduction. J Phys Chem B 2009;113:4582-9.

[129] Razaq A, Nyholm L, Sjödin M, Strømme M, Mihranyan A. Paperbased energy-storage devices comprising carbon fiber-reinforced polypyrrole-cladophora nanocellulose composite electrodes. Adv Energy Mater 2012;2:445-54.

[130] Carlsson DO, Sjödin M, Nyholm L, Strømme M. A comparative study of the effects of rinsing and aging of polypyrrole/nanocellulose composites on their electrochemical properties. J Phys Chem B 2013;117:3900-10.

[131] Nyström G, Mihranyan A, Razaq A, Lindström T, Nyholm L, Strømme M. A nanocellulose polypyrrole composite based on microfibrillated cellulose from wood. J Phys Chem B 2010;114:4178-82.

[132] Wang H, Bian L, Zhou P, Tang J, Tang W. Core-sheath structured bacterial cellulose/polypyrrole nanocomposites with excellent conductivity as supercapacitors. J Mater Chem A 2013;1: $578-84$.

[133] Liew SY, Thielemans W, Walsh DA. Electrochemical capacitance of nanocomposite polypyrrole/cellulose films. J Phys Chem C 2010;114:17926-33.
[134] Yuan L, Yao B, Hu B, Huo K, Chen W, Zhou J. Polypyrrole-coated paper for flexible solid-state energy storage. Energy Environ Sci 2013;6:470-6.

[135] Kim SY, Hong J, Palmore GTR. Polypyrrole decorated cellulose for energy storage applications. Synth Met 2012;162:1478-81.

[136] Milczarek G, Inganäs $O$. Renewable cathode materials from biopolymer/conjugated polymer interpenetrating networks. Science 2012;335:1468-71.

[137] Peng C, Hu D, Chen GZ. Theoretical specific capacitance based on charge storage mechanisms of conducting polymers: comment on 'Vertically oriented arrays of polyaniline nanorods and their super electrochemical properties'. Chem Commun 2011;47: $4105-7$.

[138] Zhang H, Cao G, Wang Z, Yang Y, Shi Z, Gu Z. High-rate lithium-ion battery cathodes using nanostructured polyaniline/carbon nanotube array composites. Electrochem Solid-State Lett 2008;11-12:A223-5

139] Zhou Y, Qin ZY, Li L, Zhang Y, Wei YL, Wang LF, Zhu MF. Polyaniline/multi-walled carbon nanotube composites with core-shell structures as supercapacitor electrode materials. Electrochim Acta 2010;55:3904-8.

[140] Lin H, Li L, Ren J, Cai Z, Qiu L, Yang Z, Peng H. Conducting polymer composite film incorporated with aligned carbon nanotubes for transparent, flexible and efficient supercapacitor. Sci Rep 2013;3, $1353 / 1-6$

141] Pääkkö M, Vapaavuori J, Silvennoinen R, Kosonen H, Ankerfors M, Lindström T, Berglund LA, Ikkala O. Long and entangled native cellulose I nanofibers allow flexible aerogels and hierarchically porous templates for functionalities. Soft Matter 2008;4: 2492-9

[142] Qaiser AA, Hyland MM, Patterson DA. Surface and charge transport characterization of polyaniline-cellulose acetate composite membranes. J Phys Chem B 2011;115:1652-61.

[143] Lee HJ, Chung TJ, Kwon HJ, Kim HJ, Tze WTY. Fabrication and evaluation of bacterial cellulose-polyaniline composites by interfacial polymerization. Cellulose 2012;19:1251-8.

[144] Wang H, Zhu E, Yang J, Zhou P, Sun D, Tang W, Bacterial cellulose nanofiber-supported polyaniline nanocomposites with flake-shaped morphology as supercapacitor electrodes. J Phys Chem C 2012;116:13013-9.

[145] Peng H, Ma G, Ying W, Wang A, Huang H, Lei Z. In situ synthesis of polyaniline/sodium carboxymethyl cellulose nanorods for high-performance redox supercapacitors. J Power Sources 2012;211:40-5

[146] Zhang X, Lin Z, Chen B, Zhang W, Sharma S, Gu W, Deng Y. Solid-state flexible polyaniline/silver cellulose nanofibrils aerogel supercapacitors. J Power Sources 2014;246:283-9.

[147] Zhai Y, Dou Y, Zhao D, Fulvio PF, Mayes RT, Dai S. Carbon materials for chemical capacitive energy storage. Adv Mater 2011;23:4828-50.

[148] Dai LM, Chang DW, Baek JB, Lu W. Carbon nanomaterials for advanced energy conversion and storage. Small 2012;8:1130-66.

[149] Candelaria SL, Shao YY, Zhou W, Li XL, Xiao J, Zhang JG, Wang Y, Liu J, Li JH, Cao GZ. Nanostructured carbon for energy storage and conversion. Nano Energy 2012;1:195-220.

[150] Su DS, Schlögl R. Nanostructured carbon and carbon nanocomposites for electrochemical energy storage applications. ChemSusChem 2010;3:136-68.

[151] Gui Z, Zhu H, Gillette E, Han X, Rubloff GW, Hu L, Lee SB. Natural cellulose fiber as substrate for supercapacitor. ACS Nano 2013:7:6037-46.

[152] Pushparaj VL, Shaijumon MM, Kumar A, Murugesan S, Ci L, Vajtai R, Linhardt RJ, Nalamasu O, Ajayan PM. Flexible energy storage devices based on nanocomposite paper. Proc Natl Acad Sci USA 2007; 104:13574-7

[153] Gao K, Shao Z, Wang X, Zhang Y, Wang W, Wang F. Cellulose nanofibers/multi-walled carbon nanotube nanohybrid aerogel for all-solid-state flexible supercapacitors. RSC Adv 2013;3: 15058-64.

[154] Zhang X, Lin Z, Chen B, Sharma S, Wong CP, Zhang W, Deng Y. Solidstate, flexible, high strength paper-based supercapacitors. J Mater Chem A 2013;1:5835-9.

[155] Hu L, Choi JW, Yang Y, Jeong S, La Mantia F, Cui LF, Cui Y. Highly conductive paper for energy-storage devices. Proc Natl Acad Sci USA 2009;106:21490-4.

[156] Hu L, Zheng G, Yao J, Liu N, Weil B, Eskilsson M, Karabulut E, Ruan Z, Fan S, Bloking JT, McGehee MD, Wågberg L, Cui Y. Transparent and conductive paper from nanocellulose fibers. Energy Environ Sci 2013;6:513-8. 
[157] Hu L, Liu N, Eskilsson M, Zheng G, Mcdonough J, Wågberg L, Cui Y. Silicon-conductive nanopaper for Li-ion batteries. Nano Energy 2013;2:138-45

[158] Huang J, Zhu H, Chen Y, Preston C, Rohrbach K, Cumings J, Hu L. Highly transparent and flexible nanopaper transistors. ACS Nano 2013;7:2106-13.

[159] Zheng G, Hu L, Wu H, Xie X, Cui Y. Paper supercapacitors by a solvent-free drawing method. Energy Environ Sci 2011;4:3368-73.

[160] Chen X, Zhu H, Liu C, Chen YC, Weadock N, Rubloff G, Hu L. Role of mesoporosity in cellulose fibers for paper-based fast electrochemical energy storage. J Mater Chem A 2013;1:8201-8.

[161] Palomares V, Serras P, Villaluenga I, Hueso KB, Carretero-González J, Rojo T. Na-ion batteries, recent advances and present challenges to become low cost energy storage systems. Energy Environ Sci 2012;5:5884-901.

[162] Guo SJ, Dong SJ. Graphene nanosheet: synthesis, molecular engineering, thin film, hybrids, and energy and analytical applications. Chem Soc Rev 2011;40:2644-72.

[163] Weng Z, Su Y, Wang DW, Li F, Du J, Cheng HM. Graphene-cellulose paper flexible supercapacitors. Adv Energy Mater 2011;1:917-22.

[164] Kang YR, Li YL, Hou F, Wen YY, Su D. Fabrication of electric papers of graphene nanosheet shelled cellulose fibres by dispersion and infiltration as flexible electrodes for energy storage. Nanoscale 2012;4:3248-53.

[165] Liu WW, Yan XB, Lang JW, Peng C, Xue QJ. Flexible and conductive nanocomposite electrode based on graphene sheets and cotton cloth for supercapacitor. J Mater Chem 2012;22:17245-53.
[166] Gao K, Shao Z, Li J, Wang X, Peng X, Wang W, Wang F. Cellulose nanofiber-graphene all solid-state flexible supercapacitors. J Mater Chem A 2013;1:63-7.

[167] Gao K, Shao Z, Wu X, Wang X, Zhang Y, Wang W, Wang F. Paperbased transparent flexible thin film supercapacitors. Nanoscale 2013;5:5307-11

[168] Liang Y, Tao Z, Chen J. Organic electrode materials for rechargeable lithium batteries. Adv Energy Mater 2012;2:742-69.

[169] Chen H, Armand M, Demailly G, Dolhem F, Poizot P, Tarscon JM. From biomass to a renewable $\mathrm{Li}_{x} \mathrm{C}_{6} \mathrm{O}_{6}$ organic electrode for sustainable Li-ion batteries. ChemSusChem 2008;1: 348-55.

[170] Chen H, Armand M, Courty M, Jiang M, Grey CP, Dolhem F, Tarascon JM, Poizot P. Lithium salt of tetrahydroxybenzoquinone: toward the development of a sustainable Li-ion battery. J Am Chem Soc 2009;131:8984-8.

[171] Armand M, Grugeon S, Vezin H, Laruelle S, Ribière P, Poizot P, Tarascon JM. Conjugated dicarboxylate anodes for Li-ion batteries. Nat Mater 2009;8:120-5.

[172] Walker W, Grugeon S, Mentre O, Laruelle S, Tarascon JM, Wud F. Ethoxycarbonyl-based organic electrode for Li-batteries. J Am Chem Soc 2010;132:6517-23.

[173] Sun K, Wei TS, Ahn BY, Seo JY, Dillon SJ, Lewis JA. 3D printing of interdigitated Li-ion microbattery architectures. Adv Mater 2013;25:4539-43. 